Article

\title{
Mechanical Properties of Concrete Pipes with Pre-Existing Cracks
}

\author{
Zongyuan Zhang ${ }^{1,2,3,4}$, Hongyuan Fang ${ }^{1,2,3,4, *}, \operatorname{Bin} \mathrm{Li}^{1,2,3,4}$ and Fuming Wang $1,2,3,4$ \\ 1 School of Water Conservancy Engineering, Zhengzhou University. Zhengzhou 450001, China; \\ zzy07240013@163.com (Z.Z.); 13523519067@163.com (B.L.); fuming573@126.com (F.W.) \\ 2 National Local Joint Engineering Laboratory of Major Infrastructure Testing and Rehabilitation Technology, \\ Zhengzhou 450001, China \\ 3 Collaborative Innovation Center of Water Conservancy and Transportation Infrastructure Safety, Henan \\ Province, Zhengzhou 450001, China \\ 4 Southern Engineering Inspection and Restoration Technology Research Institute, Huizhou 516029, China \\ * Correspondence: 18337192244@163.com; Tel.: 18337192244
}

Received: 4 February 2020; Accepted: 20 February 2020; Published: 24 February 2020

\begin{abstract}
Concrete pipes are the most widely used municipal drainage pipes in China. When concrete pipes fall into years of disrepair, numerous problems appear. As one of the most common problems of concrete pipes, cracks impact on the deterioration of mechanical properties of pipes, which cannot be ignored. In the current work, normal concrete pipes and those with pre-existing cracks are tested on a full scale under an external compressive load. The effects of the length, depth, and location of cracks on the bearing capacity and mechanical properties of the concrete pipes are quantitatively analyzed. Based on the full-scale tests, three-dimensional finite element models of normal and cracked concrete pipes are developed, and the measured results are compared with the data of the finite element analysis. It is clear that the test measurements are in good agreement with the simulation results; the bearing capacity of a concrete pipe is inversely proportional to the length and depth of the crack, and the maximum circumferential strain of the pipe occurs at the location of the crack. The strain of the concrete pipe also reveals three stages of elasticity, plasticity, and failure as the external load rises. Finally, when the load series reaches the limit of the failure load of the concrete pipe with pre-existing cracks, the pipe breaks along the crack position.
\end{abstract}

Keywords: concrete pipe; crack; circumferential strain; full-scale test; numerical simulation

\section{Introduction}

Concrete and reinforced concrete pipes enjoy considerable advantages such as high resistance to external pressure, easy manufacture, low production cost, good durability, long service life, and low price. They are widely used in the construction of urban, industrial, and mining enterprises and farmland drainage systems and have achieved good economic and social benefits. However, due to external loads, environmental corrosion, material defects, imperfect production processes, and irregular construction, concrete pipes inevitably experience problems such as cracks, corrosion, dislocation, and other diseases in the production and usage processes. The service performance of a pipe is seriously important since pipe malperformance will lead to frequent accidents-such as pipe leakage, explosion, and ground collapse-which have a huge social impact, as illustrated in Figure 1. Pipe cracks are one of the most common issues of concrete pipes, and the main associated hazards are as follows: 


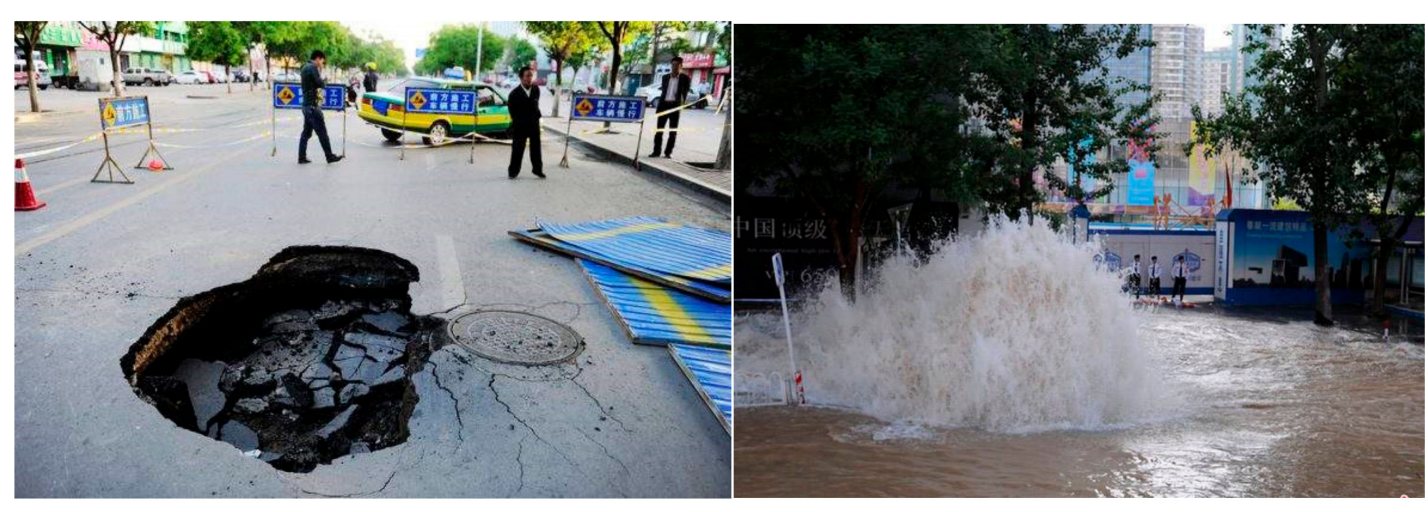

Figure 1. Pavement collapse and pipe burst caused by cracks in concrete pipes.

1) It is easy to cause the bearing capacity of the pipe to decrease, leading the pipe to break and the road to collapse.

2) The liquid can leak out of the pipe and wash out the pipe base material, thereby causing disengagement at the bottom of the pipe.

3) The liquid can infiltrate into the ground outside the pipe, which increases the operating cost of the drainage system.

Therefore, it is important to study the effect of pre-existing cracks on the mechanical properties of concrete pipes. It should be noted that this work does not consider the expansion of the initial crack.

Many researchers have conducted in-depth research on the problem of cracked pipes. Through experiments and numerical simulations, Abel (2016) verified that using Trolining lining technology to reinforce concrete pipes containing cracks can improve the bearing capacity by 35\%. The three-point test method is used to analyze the cracks of concrete pipes under external pressure [1]. Considering the curvature of the pipes, the tensile strength of concrete is $65 \%$ higher than that of the general concrete structure designs (Buda-Ozog, et al. 2017) [2]. Nourpanah and Taheri (2010), based on the evaluation of J-integration, developed a method for evaluating the integrity of such a pipe; they used a pipe model which considered a circumferential penetrating crack undergoing plastic bending [3]. Nourpanah and Taheri (2011) developed a three-dimensional detailed finite element model of a cracked pipe affected by internal pressure and bending. The ductile crack propagation was simulated by the Gurson-Tvergaard-Needleman (GTN) void plastic material model. Single edge notch tension (SENT) test specimens can exhibit fracture characteristics that are very similar to pipes [4]. Moreover, the three-dimensional (3-D) finite element methods is used to analyze buried pipes influenced by external and internal loads. The verification results of the pipe model showed that it can be used to predict the maximum stress without the need for full-scale finite element analysis (Robert, et al. 2016) [5]. Li et al. (2018) also analyzed the case of pipe construction; in their work, pipe cracking was caused by a large number of pores inside the pipe, which convert the compressive stress of the pipe into concentrated tensile stress, thereby leading to the tensile fracture of the concrete [6]. In another work, Jayadevan et al. (2004) studied the evolution of the crack tip opening displacement (CTOD) of a pipe segment with an external circumferential surface crack under pure tensile loading and tension due to internal pressure. The effects of crack depth, crack length, radius to thickness ratio, and material hardening on fracture response were studied by three-dimensional elastoplastic finite element simulation [7]. Lay and Brachman (2014) tested the physical response of a 140-D type reinforced concrete pipe with an inner diameter of $600 \mathrm{~mm}$ when buried directly under single-axle loading was measured at nominal and full factored highway design loads to examine the possible limit states of the pipe [8]. Furthermore, Silva et al. (2008) pointed out that the most important variables affecting the evaluation of characteristic values of crack opening in reinforced concrete pipes are useful height, concrete compressive strength, and pipe wall thickness [9]. Studies by BaZant and Cao (1986) have shown that unreinforced concrete pipelines can basically fail in two modes: beam failure and ring failure. According to the existing test data, the nominal stress at beam failure is much lower 
than that at ring failure. In addition, the nominal stress in either of failure modes decreases as the diameter or thickness of the pipe rises [10]. Hajali et al. (2016) modeled buried prestressed concrete cylinder pipes (PCCP), considered the interaction between the modeled pipes at the joints, simulated pipe-soil interactions and internal and external loads, and assessed the extent of PCCP damage [11]. Brachman et al. (2000) also evaluated the structural response of small-diameter buried pipes through experiments [12]. An, et al. (2012) utilized the concrete damage plasticity (CDP) model to simulate the ultimate strength of steel-fiber-reinforced concrete pipes. The parameters of their model were estimated by uniaxial stretching, compression, and four-point bending tests [13]. In another work, Hu and Liu (2012) analyzed the load bearing capacity and failure mode of PCCP using the overload damage test. The PCCP was subjected to external loading until the damage was divided into four stages: 1 ) elastic stage; 2) concrete cracking stage; 3) steel wire yielding stage; and 4) failure stage [14]. Hu et al. (2010) also studied the damage of the prestressed concrete cylinder tubes with pre-existing cracks and investigated the influence of pre-existing cracks on the ultimate strength of the pipes in the presence of external pressure through a full-scale test and numerical simulation [15]. Zhang et al. (2005) analyzed the causes, mechanisms, and prevention measures of pipe cracks according to the concrete cracking mechanism. They showed that dry shrinkage deformation, temperature deformation, structural stress, etc. are the main causes of pipeline cracks [16]. Zhu and $\mathrm{Hu}$ (2018) conducted a 1/10-size external pressure failure test on a steel sleeve concrete pipe and analyzed the bearing resistance of external pressure, the deformation characteristics of the inner and outer steel cylinders of the pipe, and the development of cracks in the core concrete [17]. The experiments of Zhao and Dou (2012) on the longitudinal wall of a pipe using a longitudinally cracked PCCP revealed that the longitudinal crack of the outer wall of the core did not significantly reduce the bearing capacity of the PCCP so the partially cracked concrete pipe could be used further [18]. Zhu and Guo (2018) conducted a study on the bearing capacity of buried pipes with corrosion defects by developing three-dimensional numerical simulation and performing experiments [19]. Dou et al. (2018) also conducted an external compressive load test on a prestressed concrete cylinder pipe and studied its structural deformation law [20]. Valiente (2001) experimented on the corrosion damage of a prestressed concrete cylinder pipe and revealed the shallow cracks and corrosion areas expected during the stress corrosion cracking process through the bending and tensile tests of the material samples [21].

Most studies have focused on the problem of cracks in intact concrete pipes under external pressure. However, the purpose of the present work is to study the bearing capacity and mechanical properties of concrete pipes with pre-existing cracks. We adopt a manual cutting method to cut the pipe wall and to form the cracks and analyze the effect of an external pressure load on a concrete pipe with pre-existing cracks. At the same time, based on the ABAQUS finite element analysis (FEA), the concrete plastic damage model is selected to build a three-dimensional finite element model of the concrete pipes with pre-existing cracks. The effects of the length, depth, and location of the cracks on the mechanical properties of the concrete pipe are analyzed, and the experimental data are compared with the numerical simulation results, providing a theoretical basis for the targeted maintenance of cracked concrete pipes.

\section{3-D Finite Element Models}

\subsection{Pipe Model}

The inner diameter, the wall thickness, and the length of the pipe are 400, 47, and $500 \mathrm{~mm}$ respectively, as depicted in Figure 2. The concrete damage plastic model (CDP) proposed by Lee and Fenves [22] is also adopted. The model takes more account of the difference between the tensile and compressive properties of materials, combines the isotropic elastic damage of concrete with plastic tensile and compression to simulate the nonlinear behavior of concrete, and has strong convergence. The mechanical properties of C50 concrete pipe material are tabulated in Table 1. 


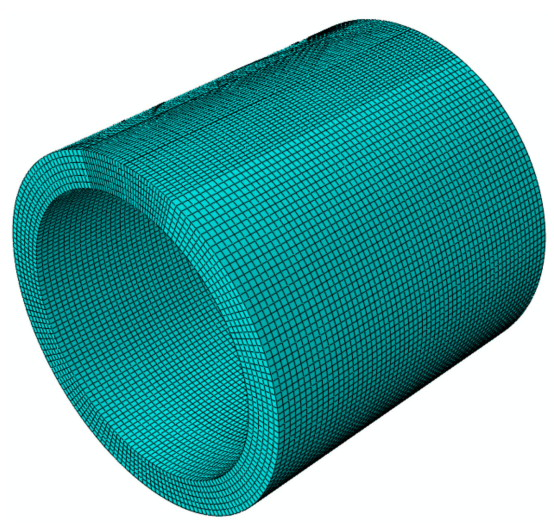

Figure 2. Whole structure mesh.

Table 1. Properties of materials used in the numerical analysis

\begin{tabular}{cc} 
Property & Value \\
\hline Concrete & $\mathrm{C} 50$ \\
Elastic modulus, $\boldsymbol{E}(\mathrm{MPa})$ & 32500 \\
Poisson's ratio, $\boldsymbol{v}$ & 0.20 \\
Density, $\boldsymbol{\rho}(\mathrm{kg} / \mathrm{m} 3)$ & 2500 \\
Compressive strength, $\sigma_{c}(\mathrm{MPa})$ & 26.6 \\
Tensile strength, $\sigma_{t}(\mathrm{MPa})$ & 2.66 \\
Dilation angle, $\psi\left({ }^{\circ}\right)$ & 30.0 \\
Eccentricity, $\boldsymbol{e}$ & 0.10 \\
The ratio of the initial equibiaxial compressive yield & 1.16 \\
stress to the initial uniaxial compressive yield stress, $n$. & \\
The ratio of the second stress invariant on the tensile \\
meridian to the second stress invariant on the \\
compressive meridian at an initial yield for any given \\
values of the pressure invariant at which the maximum \\
principal stress is negative, $k$.
\end{tabular}

\subsection{Mesh Model}

Eight-node hexahedron linear reduced-integration solid elements with hourglass control are adopted in the mesh model (C3D8R) [23-25]. In order to accurately solve the influence of the cracks on the mechanical properties of the concrete pipes, the number of mesh is increased at crack positions (Figure 2). The number of mesh nodes is 78848, and the number of elements is 66528 .

In order to further analyze the influence of mesh size on the numerical results, the sensitivity analyses of the mesh size of the model components under four different mesh discretization schemes were carried out by comparing the maximum stress of pipe $\left(\sigma_{\max }\right)$ and the calculation time $(\mathrm{T})$. The stress and calculation time under four different mesh discretization schemes are shown in Table 2. It can be seen that when the mesh number exceeds 66,500 , the maximum stress variation of the pipeline is small, but the calculation time is greatly increased.

Table 2. Sensitivity analysis of the model mesh size

\begin{tabular}{cccc}
\hline Scheme & Numbie $\mathbf{( 1 0}^{\mathbf{4}} \mathbf{)}$ & $\boldsymbol{\sigma}_{\text {max }}(\mathbf{M P a})$ & $\mathbf{T}(\mathbf{h})$ \\
\hline 1 & 6.00 & 2.44 & 1.2 \\
2 & 6.35 & 2.51 & 1.8 \\
3 & 6.65 & 2.61 & 2.2 \\
4 & 7.00 & 2.63 & 3.1 \\
\hline
\end{tabular}




\subsection{Crack Model}

Concrete pipes will produce fine cracks under the action of ultimate load, and with the continuous action of the load, the cracks will further expand. However, it is difficult to predict the initial location, propagation path, and expanded shape of the cracks. In order to quantify the uncontrollable factors of cracks, simplification is needed: on the pipe model, a crack with a width of $1 \mathrm{~mm}$ is cut along the axial direction, as displayed in Figure 3. By controlling the crack length, crack depth, and crack position, the influence of initial crack state on the bearing capacity and mechanical properties of the pipe is analyzed parametrically.

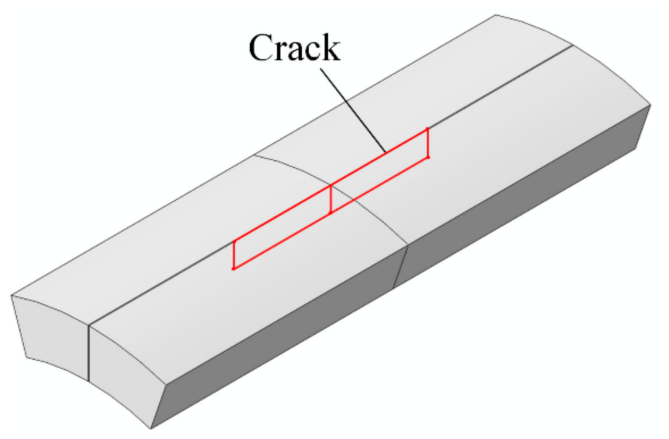

Figure 3. Crack model.

\subsection{Rubber Gasket Model}

According to the method of anti-crack external pressure test in the standard Test Methods of Concrete and Reinforced Concrete Sewer Pipes (GB/T 16752-2017) [26]. During the test, rubber gaskets should be laid on the load application part to evenly distribute the external load on the concrete pipe. Therefore, a rubber gasket model was also added to the simulation to prevent the stress concentration from causing the model results not to converge. The size of the rubber gasket model (a length of $500 \mathrm{~mm}$, a width of $100 \mathrm{~mm}$, and a thickness of $25 \mathrm{~mm}$ ) is the same as that of the rubber gasket used in the field test. The mechanical properties of the rubber gasket material are listed in Table 3.

Table 3. Mechanical properties of rubber gasket material

\begin{tabular}{ccc}
\hline$E(\mathrm{GPa})$ & $\rho\left(\mathbf{k g} \cdot \mathrm{m}^{-3}\right)$ & $v$ \\
\hline 18 & 1000 & 0.3 \\
\hline
\end{tabular}

\subsection{Failure Criteria}

When the tensile stress of the concrete pipe exceeds its ultimate tensile strength, the initial cracks will appear. The initial cracks continue to expand under the continuous action of the external load, eventually leading to the loss of the bearing capacity of the pipe. The first strength theory of material mechanics is mainly applicable to brittle materials. It is considered that when the maximum principal stress $\left(\sigma_{1}\right)$ exceeds the allowable stress $(\sigma)$, the material is destroyed. Therefore, this paper considers the first strength theory as the failure criterion of the concrete pipe. When the maximum principal stress of the concrete exceeds its ultimate tensile strength, the concrete pipe fails and cracks [27]. In the CDP constitutive model, when concrete material exceeds its ultimate tensile stress or tensile damage, cracking strain will be generated. Therefore, there are two ways to judge pipe failure: (i) whether the tensile stress exceeds its ultimate tensile strength and (ii) whether the tensile damage is greater than 1.

\subsection{Contact Surface Model}

A contact unit is arranged at the interface between the pipe and the rubber gasket to accurately simulate the transmission of the external load by the rubber gasket; the contact type is 'surface-to-surface 
contact'. The tangential behavior adopts 'penalty' contact equation; the normal behavior is 'hard contact', which indicates that there is no force transmission when the clearance between the rubber gasket and the pipe wall is greater than 0 . On the contrary, the external load transmits uniform force to the pipe wall through the contact surface. While the surfaces were sticking, the magnitude of sliding was limited to this elastic slip. Analyses in which $\mu$ (the friction factor) varied between 0.2 and 0.4 suggested that the effects of those changes in $\mu$ on the behavior of the pipe were negligible [28]. Therefore, all the analyses featured a $\mu$ value of 0.4 .

\subsection{Boundary Conditions and Loads}

In the simulation of this study, the boundary conditions of the pipeline are completely in accordance with the boundary conditions of the test pipeline in the specification [26]. The springline is not constrained, but the invert is fully constrained. The pressure-time amplitude curve is designed in ABAQUS, and the pipe is pressurized step by step, with the pressure increment at each step equal to $0.5 \mathrm{kN}$, to simulate the load application process in the test (see Figure 4).

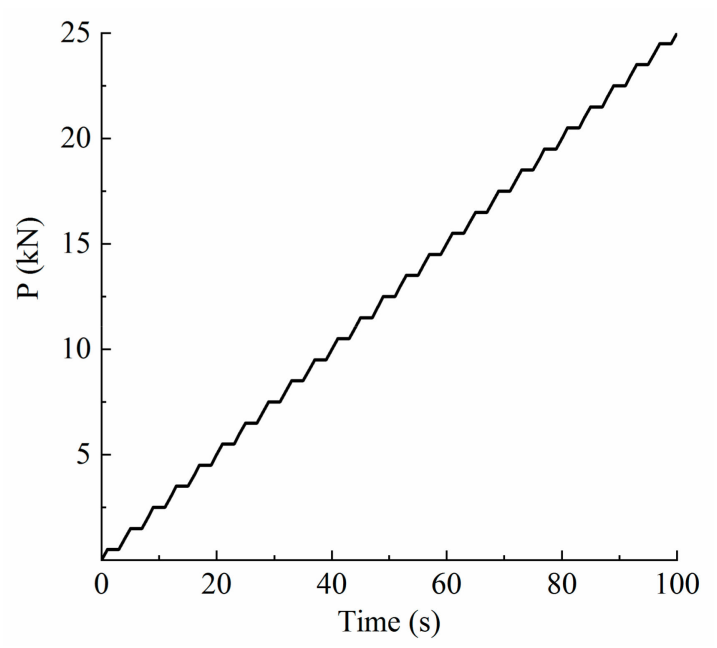

Figure 4. Pressure-time amplitude curve.

\section{Field Test}

In order to validate the three-dimensional finite element model of the concrete pipe and verify the accuracy of ABAQUS simulation results, full-scale field tests are carried out. The strength grade of the test pipe pieces is $\mathrm{C} 50$; the geometric parameters are also consistent with the numerical simulation, that is the inner diameter, the wall thickness, and the length are 400, 47, and $500 \mathrm{~mm}$ respectively. According to the specification indicated by Concrete and Reinforced Concrete Sewer Pipes (GB/T 11836-2009) [29], the specific indices and parameters are tabulated in Table 4.

Table 4. Concrete pipe specifications and indicators of external pressure load test

\begin{tabular}{|c|c|c|c|c|c|c|c|}
\hline \multirow[b]{2}{*}{$\begin{array}{c}\text { Nominal } \\
\text { Bore } \\
\mathrm{D}_{0} / \mathrm{mm}\end{array}$} & \multirow[b]{2}{*}{$\begin{array}{l}\text { Effective } \\
\text { Length } \\
\text { L/mm } \\
\geq\end{array}$} & \multicolumn{3}{|c|}{ Grade I Pipe } & \multicolumn{3}{|c|}{ Grade II Pipe } \\
\hline & & $\begin{array}{c}\text { Wall } \\
\text { Thickness } \\
\text { t/mm } \\
\geq\end{array}$ & $\begin{array}{c}\text { Failure } \\
\text { Load/(kN/m) }\end{array}$ & $\begin{array}{c}\text { Internal } \\
\text { Water } \\
\text { Pressure/ } \\
\text { MPa }\end{array}$ & $\begin{array}{c}\text { Wall } \\
\text { Thickness } \\
\text { t/mm } \\
\geq\end{array}$ & $\begin{array}{c}\text { Failure } \\
\text { Load } \\
/(\mathbf{k N} / \mathbf{m})\end{array}$ & $\begin{array}{c}\text { Internal } \\
\text { Water } \\
\text { Pressure / } \\
\text { MPa }\end{array}$ \\
\hline 350 & & 35 & 12 & & 45 & 19 & \\
\hline 400 & 1000 & 40 & 14 & 0.02 & 47 & 19 & 0.04 \\
\hline 450 & & 45 & 16 & & 50 & 19 & \\
\hline
\end{tabular}




\subsection{Crack Treatment}

Because of the randomness of naturally formed cracks is too large, it is impossible to quantitatively analyze the length, depth, and location of the cracks to control their influence on the mechanical properties of concrete pipes. Therefore, using a manual cutting method and a miniature angle grinder equipped with concrete cutting blades, the outer wall of the concrete pipe is cut along the axial direction to form pre-existing cracks, as shown in Figure 5.
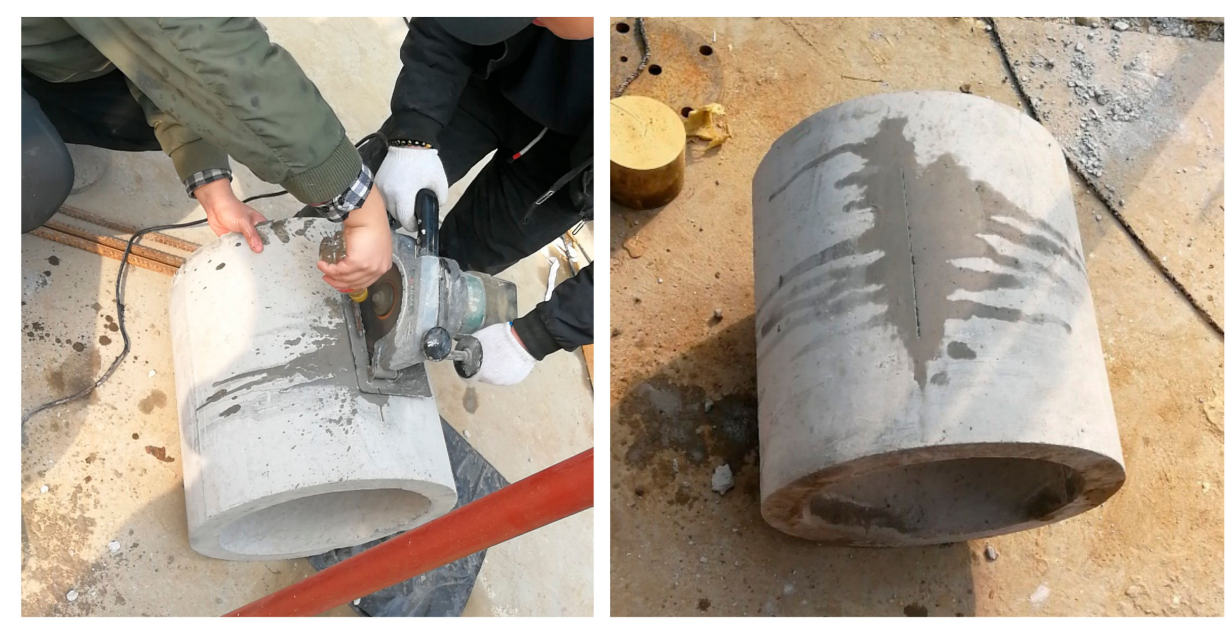

Figure 5. Cutting and forming cracks on the concrete pipe.

\subsection{Strain Gage Layout}

Three sections Section 1, Section 2.2, and Section 3.3 are arranged along the axial direction of the concrete pipe, with sections Sections 1 and 3.3 being $50 \mathrm{~mm}$ apart from the two ends of the pipe. Section 2.2 is located in the middle and placed $200 \mathrm{~mm}$ apart from the sections Sections 1 and 3.3. Considering the symmetry of the structural loading, the strain gages are only set up on the inner and outer walls of the concrete pipe in a semi-circular arrangement between $0^{\circ}$ and $180^{\circ}$; the layout of the strain gages is illustrated in Figure 6.

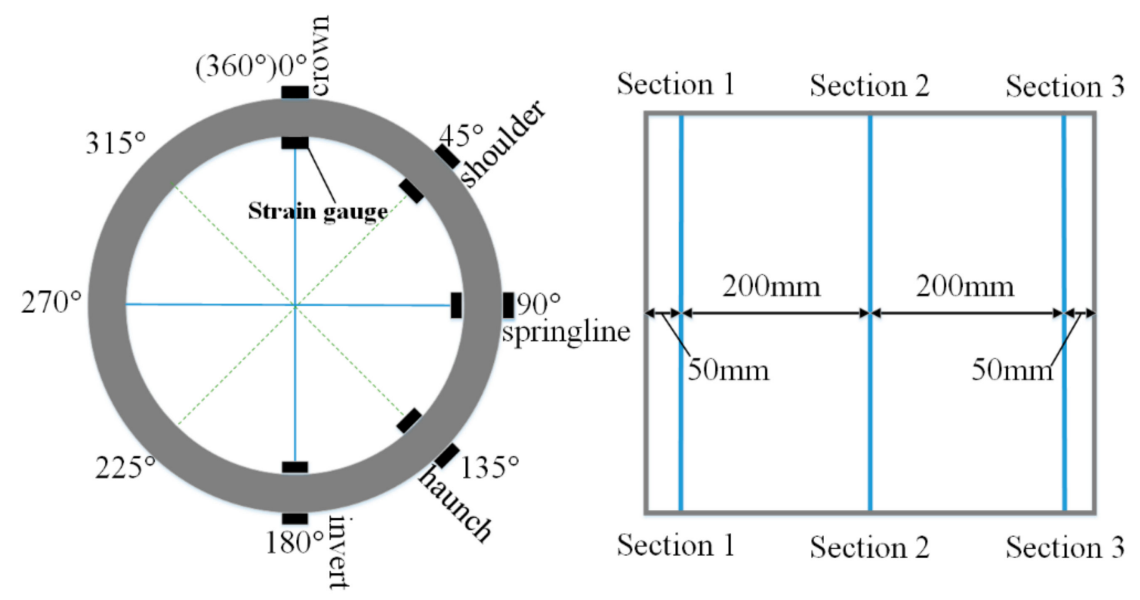

Figure 6. Layout of strain gages.

\subsection{Strain Gage Paste}

In order to better reflect the strain law of the measuring point position, a specific electrical resistance strain gage of the concrete material with the specification of $7 \times 90 \mathrm{~mm}$ and the model of BQ120-80AA-P200 are selected. In the processing of the measuring point, the position of the measuring point is first polished with fine sandpaper to ensure that the measuring point is flat and free of 
concavities and convexities; then, the surface is wiped with alcohol, and the proportioned AB glue is evenly spread on the measuring point; after being cured, the glue is polished with fine sandpaper to become smooth. Finally, the strain gage is adhered to the position with 502 glue to ensure that the strain gage is mounted to a flat surface free of curls/roughness and that no bubbles and voids are formed at the bonded interface. In order to prevent the strain gage from being affected by moisture, which consequently influences the accuracy of data collection, a layer of prepared epoxy resin is coated on its surface, as shown in Figure 7. The glued strain gage is connected to the stress-strain test system by a three-core shielded signal line, and the joint is fixed with insulating tape to avoid a short circuit.
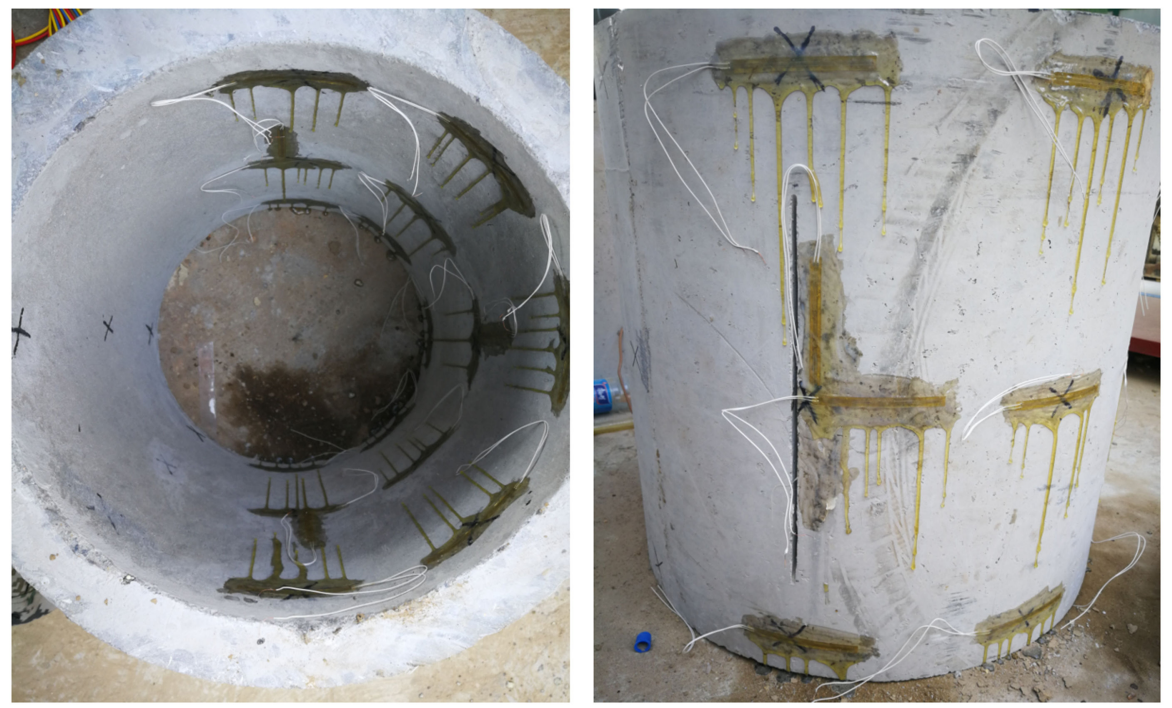

Figure 7. Gluing strain gages in position.

\subsection{Data Acquisition Instrument}

The strain acquisition instrument used herein is a 128-channel DH5921 dynamic stress-strain test and analysis system, which is specially designed for the strength and life assessment tests of large structures. It utilizes a 19-inch standard chassis structure and is expanded by a Gigabit Ethernet switch. A single computer can realize the parallel synchronous test and analysis of dynamic stress and strain signals with more than 2,000 channels. Figure 8 displays the data acquisition process.

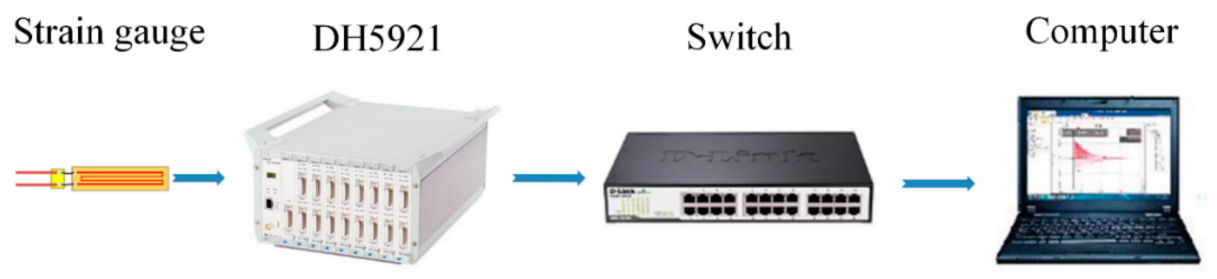

Figure 8. Data acquisition process.

\subsection{Test Device}

The external load test adopts a three-point test method, and the test device is shown in Figure 9. The external pressure test device includes a steel frame, a jack, a steel beam, a rubber gasket, and a sleeper. The external pressure test device has sufficient strength and rigidity to insure that the test process is not affected by the deformation of any parts. During the test, the load is evenly distributed on the concrete pipe body through a steel beam with a length of $500 \mathrm{~mm}$, a width of $100 \mathrm{~mm}$, and a thickness of $50 \mathrm{~mm}$. The rigidity of the steel beam should ensure that its bending degree does not exceed $1 / 720$ of the test length of the pipe body under the maximum load. A rubber pad with the same length and width as the steel beam and a thickness of $25 \mathrm{~mm}$ should be placed between the steel 
beam and the pipe body. The lower support is formed by combining two sleepers; the cross-sectional dimension of the support is $70 \mathrm{~mm}$ wide and $50 \mathrm{~mm}$ thick; it has the same length as the pipe. Moreover, the distance between the two sleepers is $50 \mathrm{~mm}$, and the contact between the sleeper and the pipe body is an outer arc with a radius of $12.5 \mathrm{~mm}$. The loading position is located in the middle of the steel beam, and the loading value is displayed by reading the pressure gage.

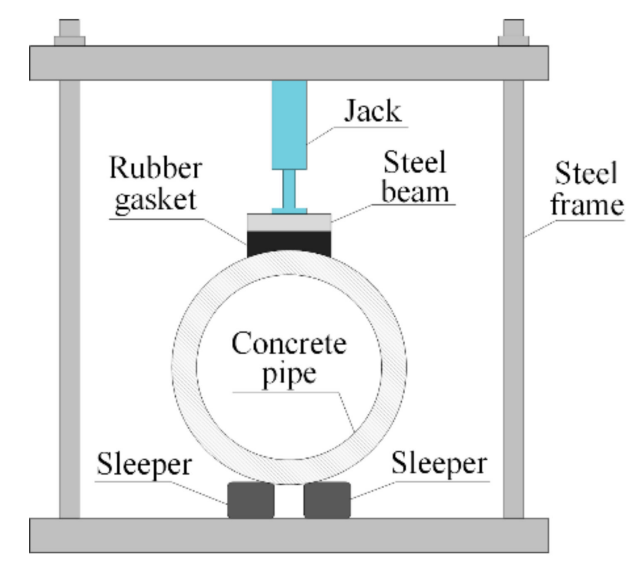

Figure 9. Loading device.

\subsection{Test Process}

Before formal loading, the 'zero drift' value of the gage is made smaller than $1.0 \mu \varepsilon$ by debugging the gage; then, the initial strain value is read, and balanced 'reset' is performed to eliminate the error in the results caused by curling of the strain gage itself or other factors.

After debugging, a hydraulic jack is used to apply the load step by step with $0.5 \mathrm{kN}$ at each level. We wait for 1-2 minutes after each stage of loading, observe the pressure gage reading, and continue to apply load when the gage reading tends to be stable; we continue the load-applying cycle until the pipe body loses its bearing capacity and breaks down.

\subsection{Determination of Failure Load}

When the pipe body is in a failure state during a loading step, the previous load level is considered as the failure load. When the failure state occurs during a loading step, the failure load is the average value of the load level at the current loading step and the load level at the previous step; when the failure state occurs after a loading step, the load value of that step is regarded as the failure load. External pressure load value, $P$, of the test is calculated by

$$
P=\frac{F}{L}
$$

where $P(\mathrm{kN} / \mathrm{m})$ is the external pressure load value; $F(\mathrm{kN})$ stands for the total load value, and $L(\mathrm{~m})$ represents the effective length of the pipe body.

\subsection{Design Conditions}

In order to explore the influences of crack length, crack depth, and crack location on the ultimate bearing capacity of the concrete pipes, 8 groups of concrete pipes were considered, and each group includes 3 specimens; thus, a total of 24 specimens are analyzed. As described in Table 5, seven groups are the concrete pipe specimens with a pre-existing crack, and the other one is an intact concrete pipe specimen used as a control group. We record and sort out the load and strain data measured in each group of the tests and consider the average value of three specimens as the test results. 
Table 5. Design condition

\begin{tabular}{|c|c|c|c|}
\hline Group & Crack Length $(\mathrm{mm})$ & Crack Depth $(\mathrm{mm})$ & Crack Location \\
\hline 1 & 400 & \multirow{3}{*}{25} & \multirow{3}{*}{ Crown } \\
\hline 2 & 300 & & \\
\hline 3 & 200 & & \\
\hline 4 & \multirow{2}{*}{300} & 20 & \multirow{2}{*}{ Crown } \\
\hline 5 & & 10 & \\
\hline 6 & \multirow{2}{*}{300} & \multirow{2}{*}{25} & Springline \\
\hline 7 & & & Invert \\
\hline
\end{tabular}

\section{Results and Discussion}

\subsection{Test Process}

Through observing the test process, it is found that by increasing the external pressure load step by step, the stress at both ends of the crack becomes larger and larger. When the tensile strength of concrete is exceeded, the pipe body suddenly breaks from the crack; the failure state is shown in Figure 10. It is clear that when the concrete pipe containing pre-existing cracks is damaged by the external pressure load, the pipe body is uniformly broken into four pieces along the crack direction. The fault zones are located at the crown, invert, and springline.

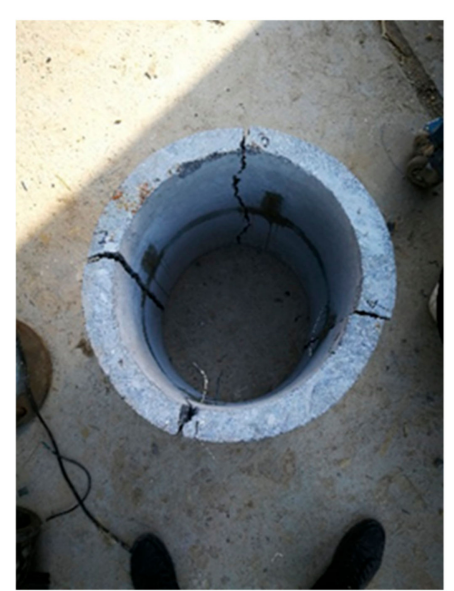

(a)

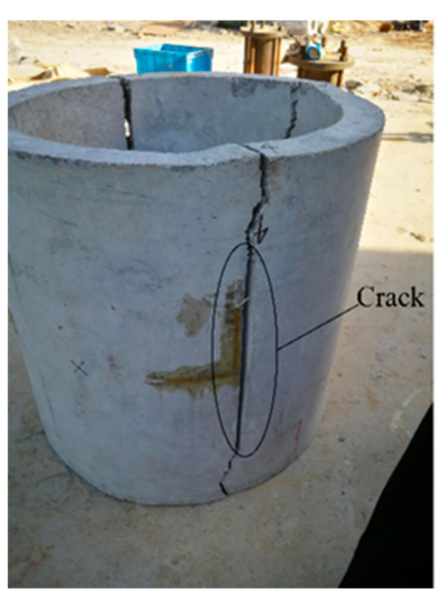

(b)

Figure 10. (a) Intact concrete pipe and (b) cracked concrete pipe.

\subsection{Comparison between Numerical and Experimental Results of the Intact Pipe}

Firstly, the stress state of the control group, which is the intact concrete pipes under an external step-by-step load, is tested. The model of the intact concrete pipe is shown in Figure 11. We increase the external pressure load step by step until the maximum principal stress of the pipe reaches the ultimate tensile strength, i.e. $2.66 \mathrm{MPa}$. As shown in Figure 12, the nephogram of the maximum principal stress of the intact pipe in the failure state shows that the largest tensile stress is on the inner wall at the crown and invert locations, followed by that of the outer wall at the springline. 


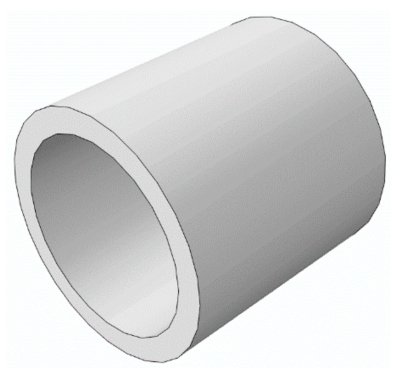

Figure 11. Intact pipe.

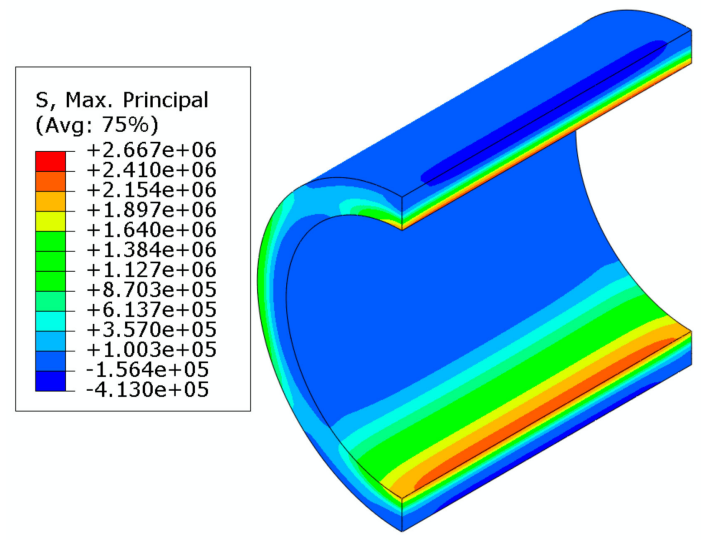

Figure 12. Nephogram of the maximum principal stress.

We extract the strains at the crown, shoulder, springline, haunch, and invert locations of the intact pipe in Section 2.2 and plot the load-strain curves respectively, as presented in Figure 13 ( $\varepsilon$ is the strain at the vertical axes of the diagrams and $\mu \varepsilon$ express microstrain, where $\varepsilon=\Delta \mathrm{L} / \mathrm{L}$ and $\left.\mu \varepsilon=\varepsilon \cdot 10^{-6}\right)$. It is clear that the distribution law and numerical value of the simulated and measured load-strain curves are basically consistent, which confirms that the test results are reliable. In addition, as can be inferred from Figure 13, in the elastic stage of the pipe, with the gradual increase of the external load, the strain at each measuring point increases linearly, and the duration of this stage is longer. With a further increase in the external load, the pipe transits from the elastic stage to the plastic stage. When the external load exceeds the ultimate bearing capacity of the pipe, the load-strain curve changes abruptly and the pipe is damaged. The transition from the elastic stage to the plastic stage and then to final failure is very short, which fully demonstrates the brittleness of the concrete materials.

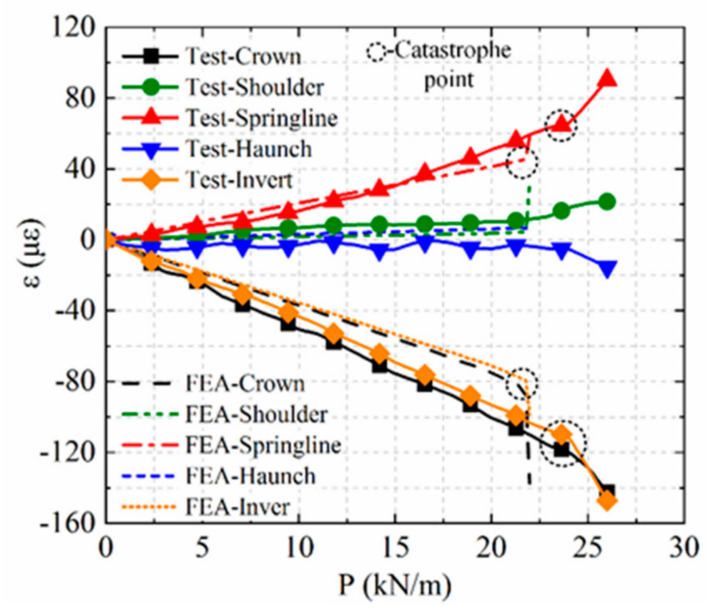

(a)

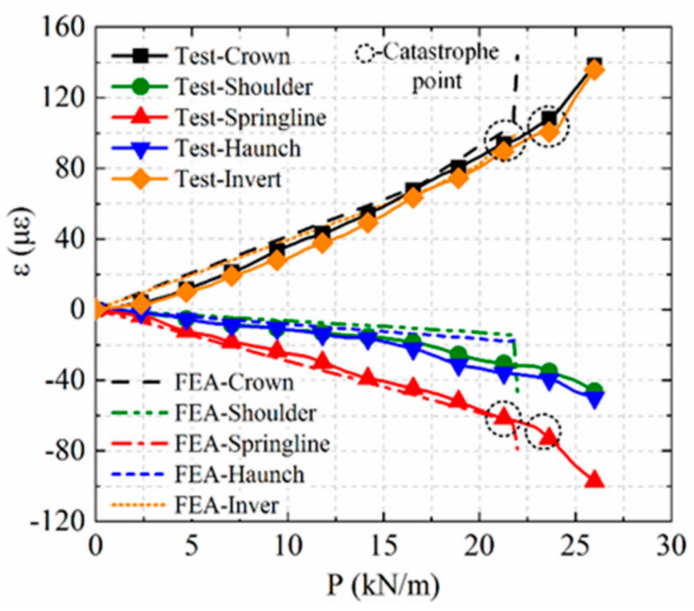

(b)

Figure 13. Comparison of load-strain curves of the intact pipe: (a) outer wall and (b) inner wall. 
In Figure 13a, the simulated load-strain curve of the outer wall of the pipe states that when the load reaches $22 \mathrm{kN} / \mathrm{m}$, the strain value of the outer wall at the springline first changes abruptly. However, the simulated load-strain curve of the inner wall of the pipe (Figure 13b) shows that when the load reaches $21.7 \mathrm{kN} / \mathrm{m}$, the strain at the crown and invert first changes suddenly. It demonstrates that, under an external load, the intact pipe is first damaged on the inner wall at the crown and invert. The measured load curve also confirms that the failure load of the intact pipe is about $23 \mathrm{kN} / \mathrm{m}$, and the error value is only $5.7 \%$, which further verifies the reliability of the simulation results.

\subsection{Comparison between Simulated and Measured Results of the Pipes with Pre-Existing Cracks}

On the basis of studying the bearing capacity of concrete pipes under the condition of external step-by-step loading, this section further analyzes the influences of the length, depth, and location of pre-existing cracks on the bearing capacity of concrete pipes.

\subsubsection{Effect of Crack Length}

On the crown of the concrete pipe, $25 \mathrm{~mm}$-deep cracks with a length of 400, 300, and $200 \mathrm{~mm}$ are prefabricated to study the influence of crack length on the mechanical response of the pipe, as displayed in Figure 14. The load is applied to the pipes with pre-existing cracks step by step. The stress nephogram, when the maximum principal stress of the pipe reaches the ultimate tensile strength (2.66 MPa), is illustrated in Figure 15. It is clear that the stress distribution of the pipe obviously varies with the change in the crack length and is mainly concentrated at the crown position. The distribution area of compressive stress at the bottom of the crack and tensile stress at the inner wall of the crown increase with an increase in crack length, which will lead to a significant decrease in the ultimate bearing capacity of the concrete pipe.

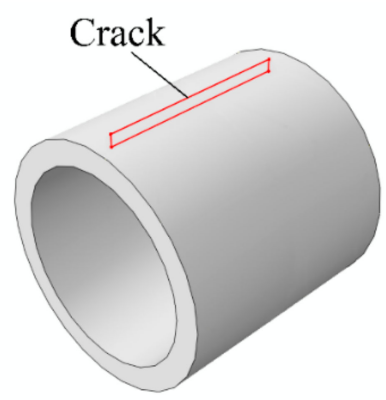

(a)

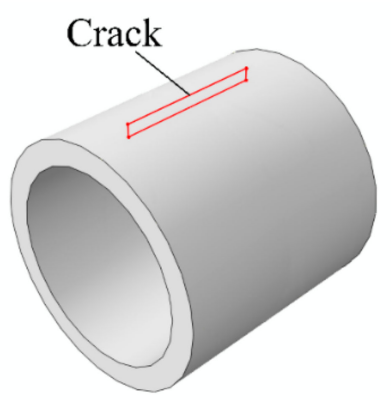

(b)

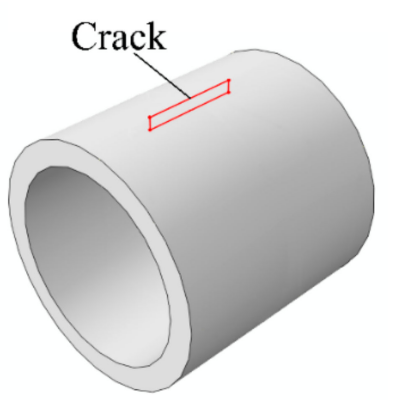

(c)

Figure 14. Pipes containing cracks with different lengths: (a) $400 \mathrm{~mm}$, (b) $300 \mathrm{~mm}$, and (c) $200 \mathrm{~mm}$.

(1) Load-strain curve

Because the prefabricated cracks with different lengths are located at the crown, and the concrete pipes are generally subjected to tensile damage, under the action of the external ultimate load, the first damaged parts of the pipe are the outer wall at the springline and the inner wall at the crown. Therefore, the points corresponding to the positions where the strain gages are affixed to the outer wall at the springline and to the inner wall at the crown are selected in Section 2.2 of the pipe model, and load-strain curves are drawn, as depicted in Figure 16. It is clear that under the action of the external load, the strain of the outer wall at the springline and that of the inner wall at the crown rise with an increase in the external step-by-step load, which can roughly be divided into three stages: 1) elastic stage: the strain at the top of the pipe changes linearly in this stage, indicating that the pipe is in the elastic stage; 2) elastic-plastic stage: when reaching a certain load value, the strain begins to follow a non-linear trend; thus, it can be considered that the pipe enters the plastic stage, and the process in this stage is extremely short; 3) plastic-failure stage: when the load reaches the limit of the failure load, the strain varies abruptly, indicating that the crown cracks and that the pipe loses its bearing capacity. 


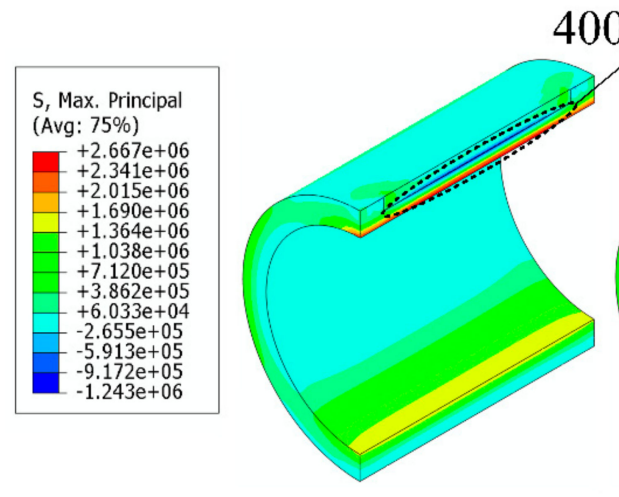

(a)

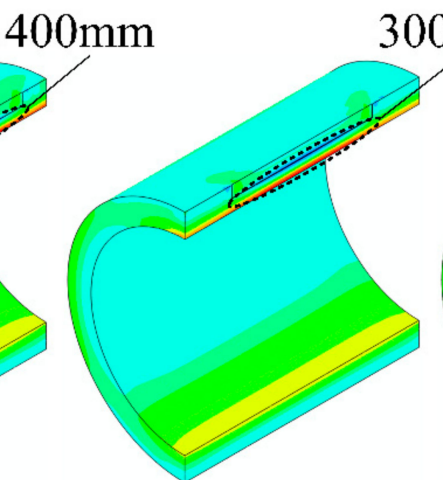

(b)

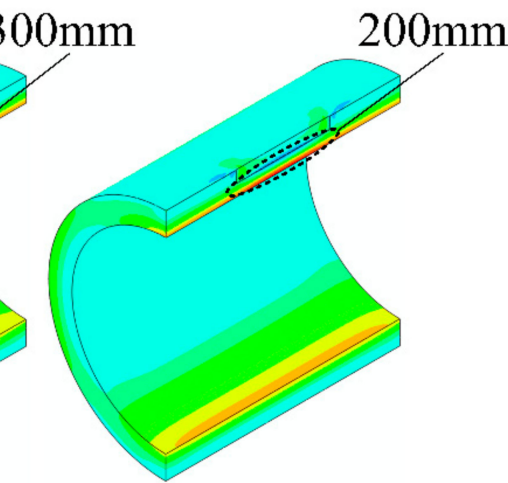

(c)

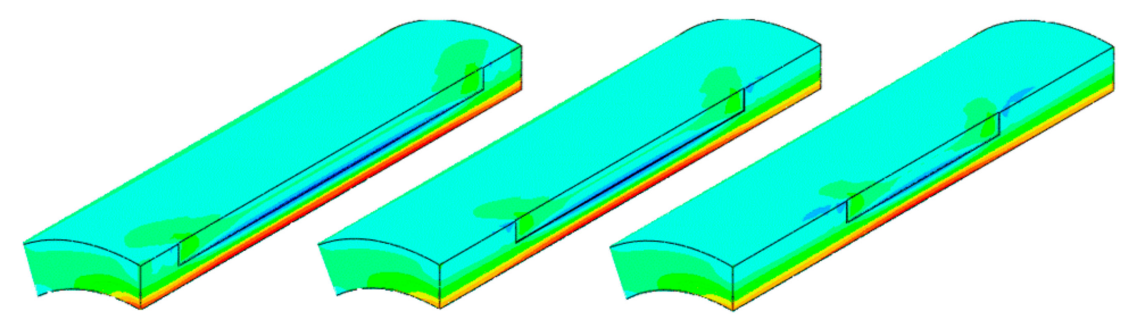

Note: Enlarged diagram of the results near the crack

Figure 15. Nephogram of the maximum principal stress of the pipes containing cracks with different lengths: (a) $400 \mathrm{~mm}$, (b) $300 \mathrm{~mm}$, and (c) $200 \mathrm{~mm}$.

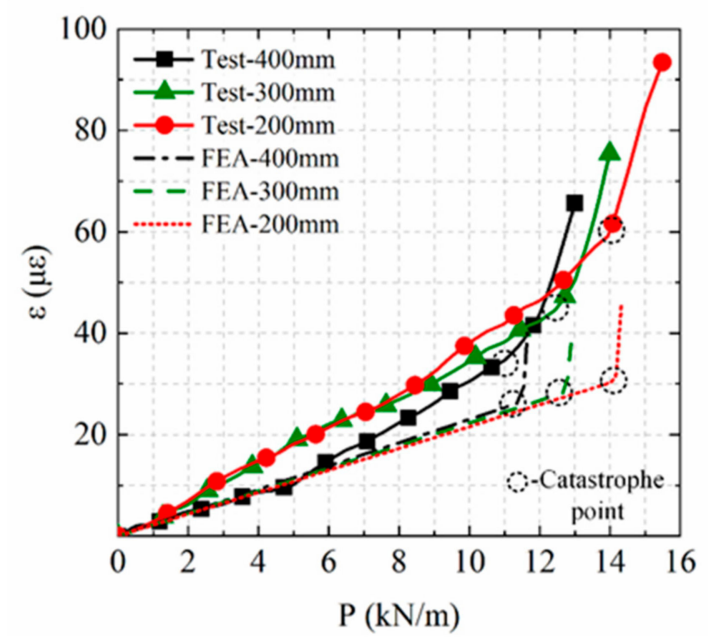

(a)

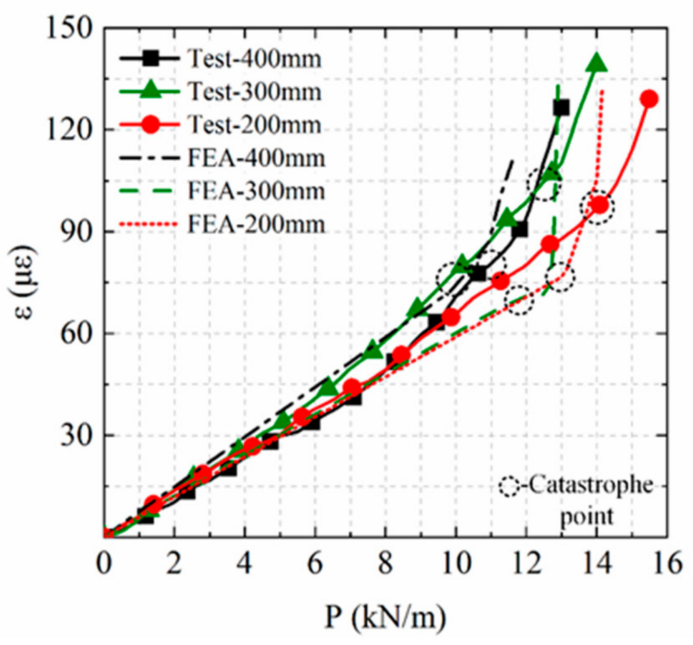

(b)

Figure 16. Load-strain curves of the pipes containing cracks with different lengths: (a) outer wall at the springline and (b) inner wall at the crown.

The measured and simulated curves of the outer wall at the springline (Figure 16a) confirm that when the pipe loses its bearing capacity, the largest strain, with the measured value of $59.6 \mu \varepsilon$ and the simulated value of $30.5 \mu \varepsilon$, occurs on the pipe with a crack length of $200 \mathrm{~mm}$. On the other hand, the strain of the pipe with a crack length of $400 \mathrm{~mm}$, having the measured value of $35.3 \mu \varepsilon$ and the simulated value of $26.6 \mu \varepsilon$, is the smallest. Therefore, the longer the crack length, the smaller the tensile strain. According to Figure 16b, due to the influence of the crack at the crown, the strain of the 
inner wall at the crown is too large, which implies that the crack is the place where the concrete pipe is extremely vulnerable. When the pipe loses its bearing capacity, the measured curve represents a maximum strain of $104.6 \mu \varepsilon$ for a crack length of $300 \mathrm{~mm}$. Also, according to the simulation curve, when the crack length is $400 \mathrm{~mm}$, the maximum strain reaches $76.8 \mu \varepsilon$.

The analysis of the load-strain curve of the pipe with a $400 \mathrm{~mm}$-long crack: According to Figure 16a, the simulated and measured curves of the outer wall at the springline respectively reveal that when the load reaches $11.4 \mathrm{kN} / \mathrm{m}$ and $11.2 \mathrm{kN} / \mathrm{m}$, the strain changes abruptly and the outer wall cracks at the crown. In Figure 16b, the simulated and measured curves of the inner wall at the crown respectively show that when the load reaches $10 \mathrm{kN} / \mathrm{m}$ and $11 \mathrm{kN} / \mathrm{m}$, the inner wall cracks at the crown. Therefore, it can be concluded that the failure load of the pipe with pre-existing cracks obtained by the simulation is about $10 \mathrm{kN} / \mathrm{m}$, and the value calculated experimentally is about $11 \mathrm{kN} / \mathrm{m}$. In fact, the existence of cracks causes the bearing capacity of the concrete at the crown to drop, while the inner wall is under tension at the crown. Therefore, under the action of an external load, the inner wall cracks at the crown before the outer wall breaks at the springline.

Therefore, when the pipe loses its bearing capacity, the simulated failure load values of the pipes having cracks with a length of 400,300, and $200 \mathrm{~mm}$ are respectively 10,11.7, and $13.2 \mathrm{kN} / \mathrm{m}$, and their ultimate bearing capacities are respectively reduced by 54,46 , and $39 \%$ compared to the failure load values of the intact pipes. However, the measured results disclose that the failure load values of the concrete pipes having cracks with lengths of 400, 300, and $200 \mathrm{~mm}$ are 11, 12.5, and $14 \mathrm{kN} / \mathrm{m}$ respectively. Compared with the measured failure load values of the intact pipes, the ultimate bearing capacities of the concrete pipes are reduced by 52,49 , and $43 \%$ respectively. These findings confirm that the length of the crack has a significant impact on the bearing capacity of the concrete pipes.

(2) Circumferential strain

In order to analyze the influence of cracks on the ultimate bearing capacity of the concrete pipes in detail, the strain of the pipes containing cracks with different lengths is extracted in eight circumferential positions, namely $0,45,90,135,180,225,270$, and $315^{\circ}$, under a destructive load, as presented in Figure 17.

As can be inferred from Figure 17, the circumferential strains on the outer wall and inner wall of the pipes are symmetrically distributed in the center. The crown and invert of the outer wall of the pipe are under pressure in the range of $90^{\circ}\left(315-45^{\circ}\right.$ and $\left.135-225^{\circ}\right)$, while from the shoulder to the haunch is under tension in the range of $90^{\circ}\left(45-135^{\circ}\right.$ and $\left.225-315^{\circ}\right)$; the springline $\left(90^{\circ}\right.$ and $\left.270^{\circ}\right)$ is under the maximum tensile stress. The crown and invert of the inner wall of the pipe are under tension in the range of $90^{\circ}\left(315-45^{\circ}\right.$ and $\left.135-225^{\circ}\right)$, while from the shoulder to the haunch is under pressure in the range of $90^{\circ}\left(45-135^{\circ}\right.$ and $\left.225-315^{\circ}\right)$; the largest tensile stress is seen at the crown and invert $\left(0^{\circ}\right.$ and $\left.180^{\circ}\right)$. Therefore, it can be concluded that under the action of an external load, the crown, invert, and springline locations are the vulnerable parts of the concrete pipe. In Figure 17a,b, due to the influence of the pre-existing cracks at the crown, the strains on the inner and outer walls of the crown and invert locations are different. At the crown $\left(0^{\circ}\right)$, the simulation curve states that the largest and smallest strains are respectively achieved at the crack length of 400 and $200 \mathrm{~mm}$, which indicates that the larger the crack length is, the more easily the pipe is damaged.

\subsubsection{Effect of Crack Depth}

Cracks with a depths of 25,20, and $15 \mathrm{~mm}$ having a length of $300 \mathrm{~mm}$ are created at the crown of the concrete pipe to study the influence of crack depth on the mechanical response of the pipe (see Figure 18). An external load is applied to the pipes with the pre-existing cracks step by step. The stress nephogram, when the maximum principal stress of the pipe reaches the ultimate tensile strength $(2.66$ $\mathrm{MPa})$, is illustrated in Figure 19. 


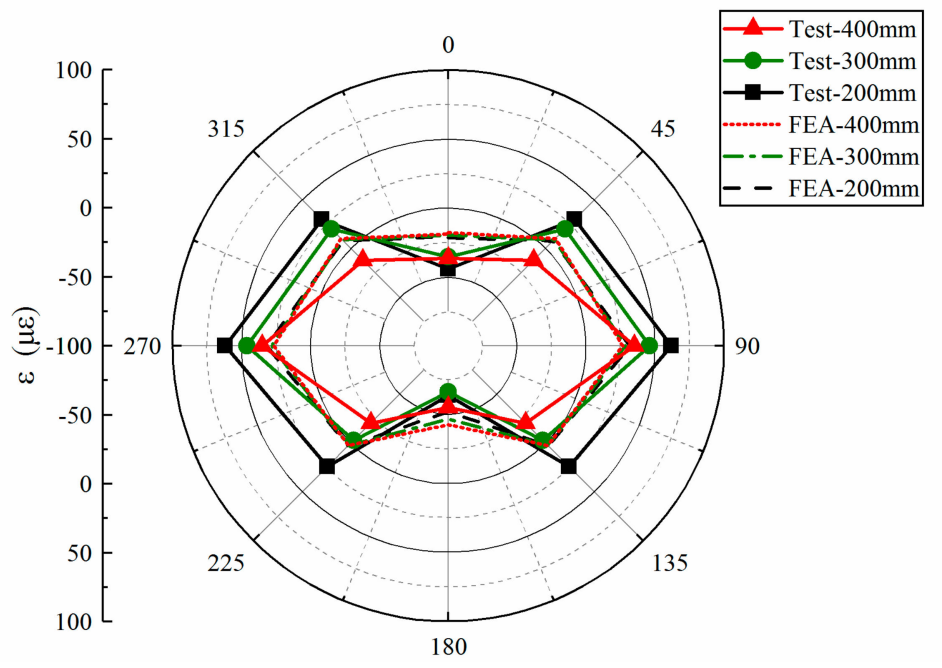

(a)

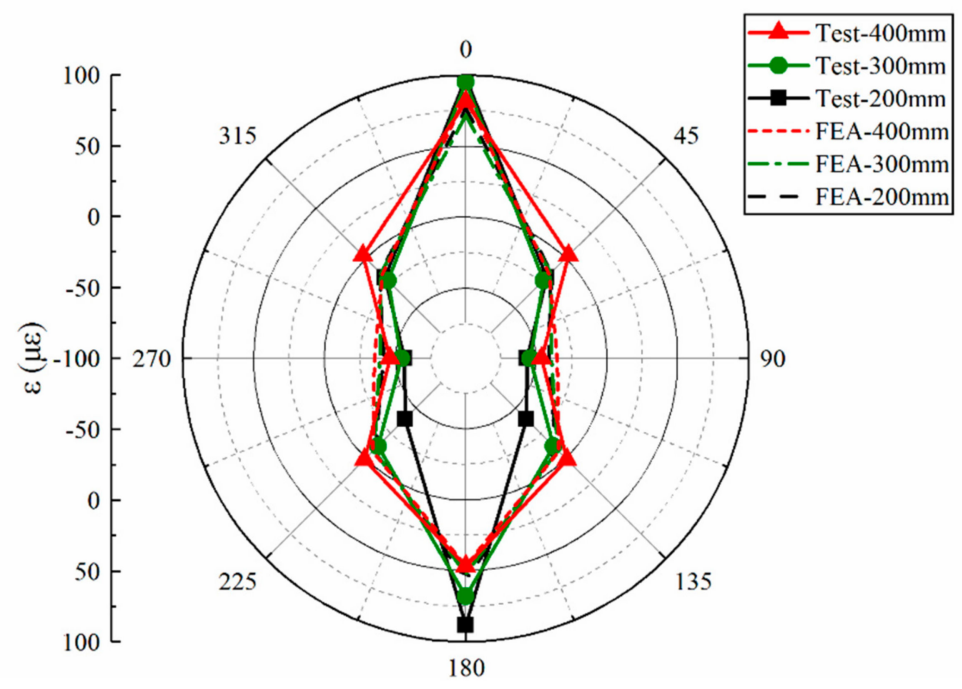

(b)

Figure 17. Circumferential strain curve of the pipes containing cracks with different lengths: (a) outer wall and (b) inner wall.

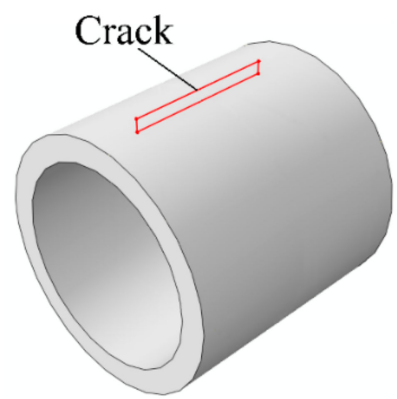

(a)

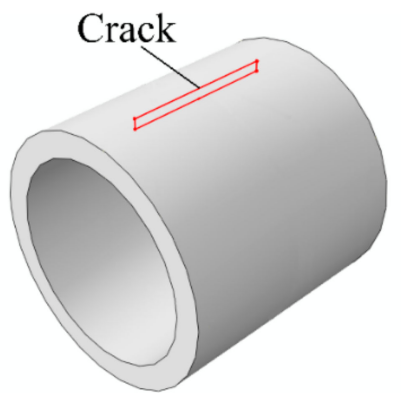

(b)

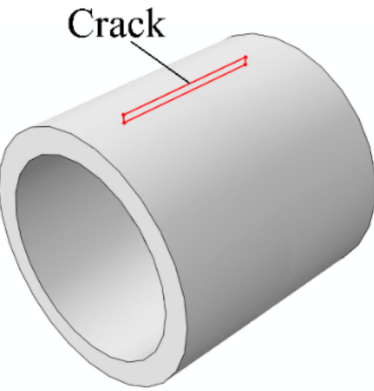

(c)

Figure 18. Pipes containing cracks with different depths: (a) $25 \mathrm{~mm}$, (b) $20 \mathrm{~mm}$, and (c) $15 \mathrm{~mm}$. 


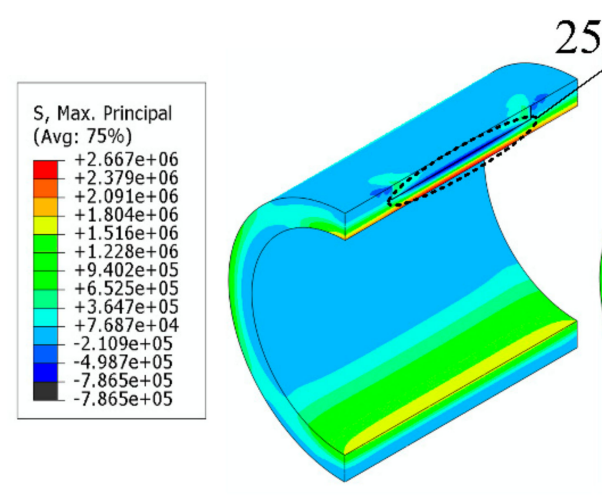

(a)

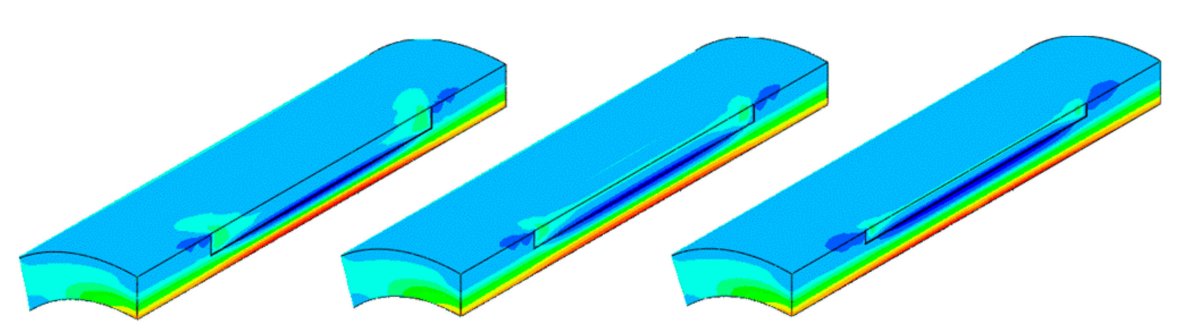

Note: Enlarged diagram of the results near the crack

Figure 19. Nephogram of the maximum principal stress of the pipes containing cracks with different depths (a) $25 \mathrm{~mm}$, (b) $20 \mathrm{~mm}$, and (c) $15 \mathrm{~mm}$.

From the distribution of the maximum principal stress in Figure 19, the difference of stress distribution in the crack at the crown is clearly obvious; the distribution area of compressive stress at the bottom of the crack decreases by increasing crack depth. The tensile stress on the inner wall at the crown rises with an increase in crack depth. The highest stress concentration is obtained at both ends of the 25 mm-deep crack

(1) Load-strain curve

Same as above, we draw and compare the load-strain curves of the outer wall at the springline and that of the inner wall at the crown in Section 2.2 of the pipes with pre-existing cracks. As delineated in Figure 20, as the external load rises step by step, the strain on the outer wall at the springline and that on the inner wall at the crown increase gradually, and the load-strain curve conforms to the change of the three stages. The simulation curve of the outer wall at the springline (Figure 20a) shows that, when the pipe loses its bearing capacity, the greater the crack depth is, the smaller the tensile strain becomes. In fact, when the crack depth is $15 \mathrm{~mm}$, the strain reaches its largest value, i.e. 31.2 $\mu \varepsilon$. According to Figure 20b, due to the existence of cracks, the strain on the inner wall at the crown is too large, indicating that the inner wall at the crown is the first part of the pipe which would be damaged. Therefore, it can be concluded that the simulated failure load values of the pipes containing cracks with depths of 25,20, and $15 \mathrm{~mm}$ are $11.7,13$, and $13.4 \mathrm{kN} / \mathrm{m}$ respectively, and their ultimate bearing capacities are reduced by 46,40 , and $38 \%$ respectively compared with the failure load values of the intact pipes. Further, the measured data reveal that the failure load values of the concrete pipes containing cracks with depths of 25,20 , and $15 \mathrm{~mm}$ are $12.5,13$, and $14 \mathrm{kN} / \mathrm{m}$ respectively. Compared with the measured failure load values of the intact pipes, the ultimate bearing capacities are reduced by 46,43 , and $39 \%$ respectively. These findings confirm that the ultimate bearing capacity of the pipe is inversely proportional to the depth of the crack. In fact, the deeper the crack is, the smaller the ultimate bearing capacity of the pipe becomes, which causes the pipe to be more vulnerable to damage. 


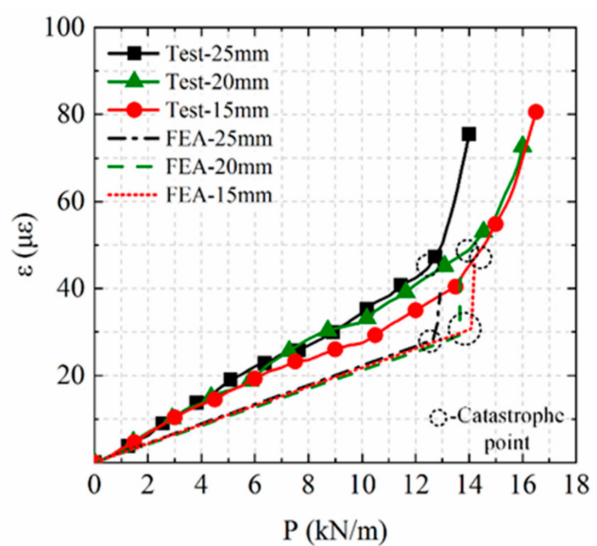

(a)

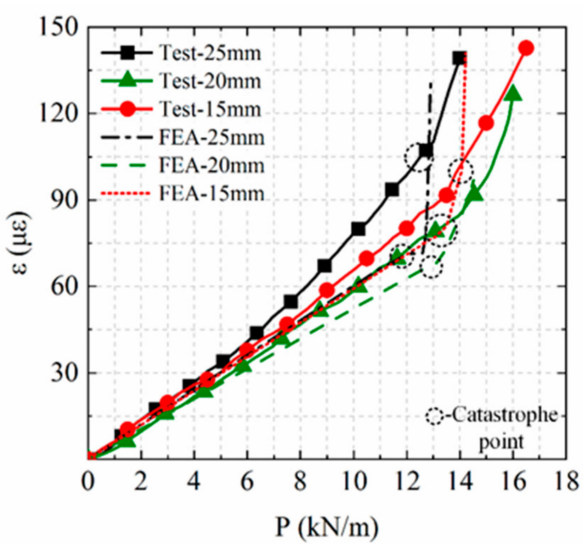

(b)

Figure 20. Load-strain curves of the pipes containing cracks with different depths: (a) outer wall at the springline and (b) inner wall at the crown.

(2) Circumferential strain

Similarly, the circumferential strains on the pipes containing cracks with different depths are extracted under the destructive load at eight locations, i.e. $0,45,90,135,180,225,270$, and $315^{\circ}$, in the circumferential direction, and the circumferential strains on the pipes containing cracks with depths of 25, 20, and $15 \mathrm{~mm}$ are analyzed. The strain curves are shown in Figure 21.

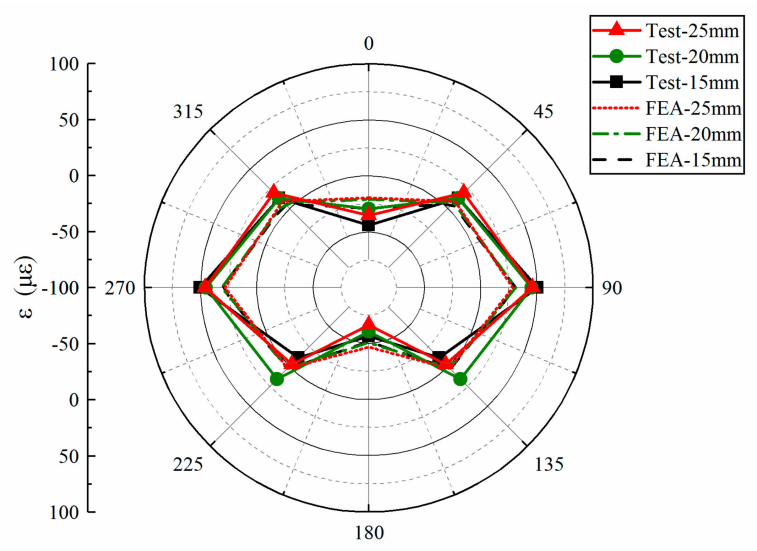

(a)

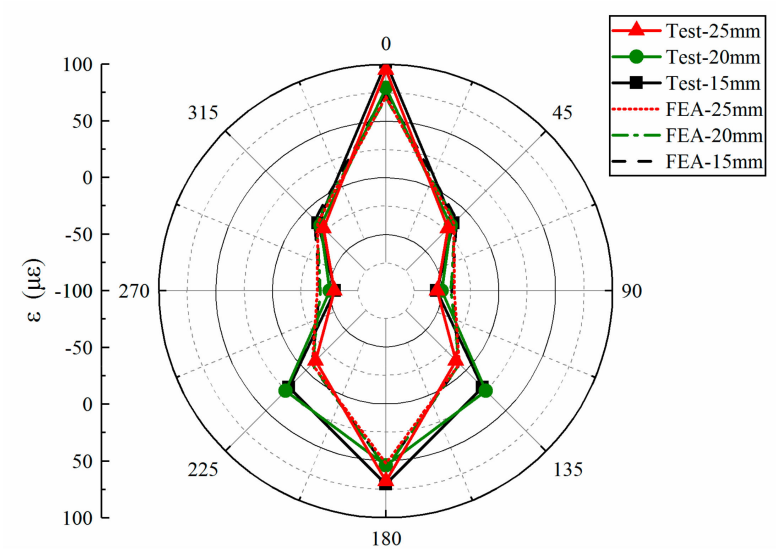

(b)

Figure 21. Circumferential strain curve of the pipes containing cracks with different depths: (a) outer wall and (b) inner wall. 
Based on Figure 21, the distribution of the circumferential strain on the inner and outer walls of the middle pipe is still highly symmetrical. At the four positions of the crown $\left(0^{\circ}\right)$, invert $\left(180^{\circ}\right)$, and springline $\left(90^{\circ}\right.$ and $\left.270^{\circ}\right)$, the strains on the inner and outer walls of the pipe are relatively large and positive but opposite to each other. However, the strains at the four positions of the shoulder $\left(45^{\circ}\right.$ and $\left.315^{\circ}\right)$ and the haunch $\left(135^{\circ}\right.$ and $\left.225^{\circ}\right)$ are relatively small, indicating that, under the action of an external load, these four positions are under relatively small stress, so they are not easily damaged. This is also consistent with the failure mode of the concrete pipes with pre-existing cracks during the test. At the position of the crown $\left(0^{\circ}\right)$ in Figure 21a,b, cracks with different depths have a greater influence on the strain, and deeper cracks significantly lower the bearing capacity of the concrete pipe.

\subsubsection{Effect of Crack Location}

In order to study the influence of crack location on the mechanical response of the concrete pipes, a pipe model with prefabricated cracks with a length of $300 \mathrm{~mm}$ and a depth of $25 \mathrm{~mm}$ at the crown, springline, and invert locations is selected as displayed in Figure 22. An external load is applied to the pipe with pre-existing cracks step by step. The stress nephogram, when the maximum principal stress of the pipe reaches the ultimate tensile strength $(2.66 \mathrm{MPa})$, is shown in Figure 23. It is inferred from the maximum principal stress distribution in Figure 23 that when the cracks are located either at the crown or at the invert, the largest tensile stress occurs on the inner wall of the crown and invert. However, when the crack is located at the springline, the stress on the bottom of the crack is small. Similarly, stress concentration occurs at both ends of the cracks at these three positions.

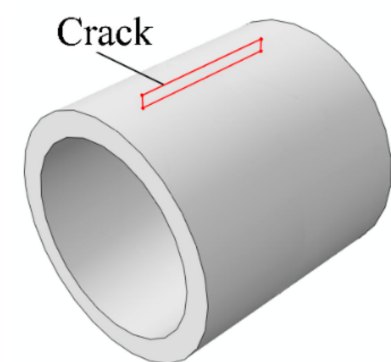

(a)

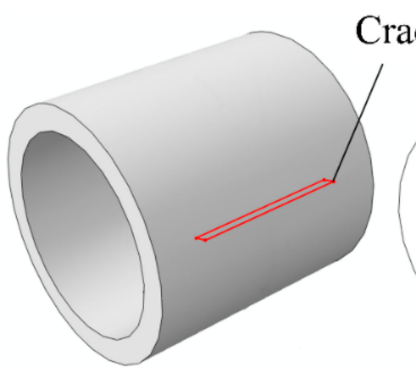

(b)

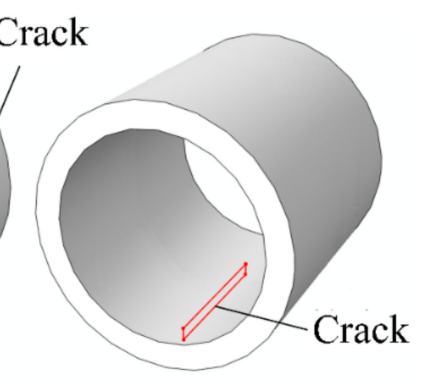

(c)

Figure 22. Pipes containing cracks at different positions: (a) crown, (b) springline, and (c) invert.

(1) Load-strain curve

At Section 2.2 of the pipe with pre-existing cracks, we draw the load-strain curves of the inner and outer walls at different crack positions as can be seen in Figure 24. The analysis of the simulated and measured load-strain curves in Figure 24 clearly proves that the load-strain curve has three stages of changes while the external load increases. At first, the strain curve of the inner wall varies abruptly, which implies that the damage first occurs on the inner wall of the pipe at the crack position. Moreover, the strain curves of the crown and invert positions basically coincide, which confirms that when the cracks are located either at the crown and or at the invert their influence on the pipe is basically the same. According to Figure $24 \mathrm{a}, \mathrm{b}$, when the crack is located either at the crown and or at the invert, the measured and/or simulated strain values are basically equal, but both are larger than the strain value when the crack is located at the springline. In fact, when the crack is located either at the crown and or at the invert, it greatly impacts on the bearing capacity of the concrete pipe, and the pipe is more easily damaged. 


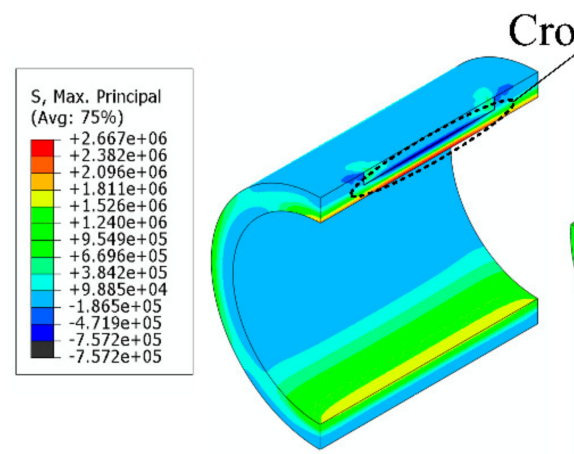

(a)

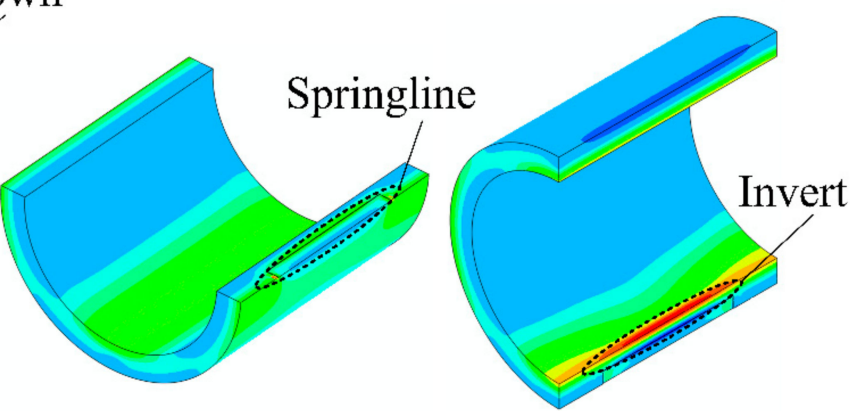

(b) (c)

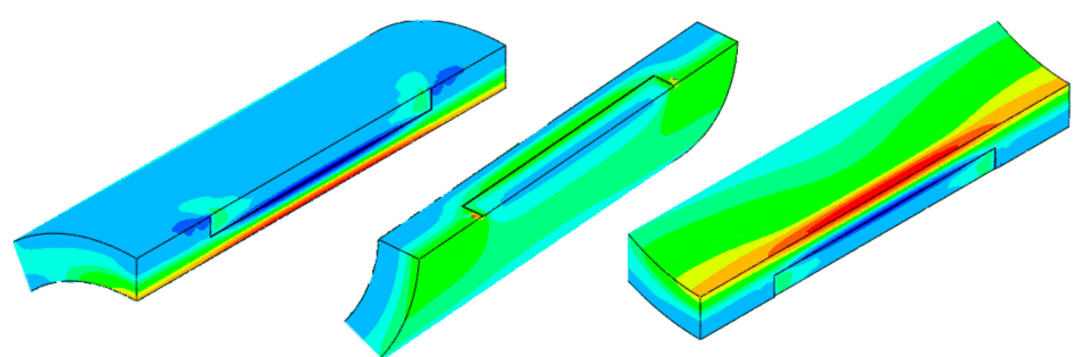

Note: Enlarged diagram of the results near the crack

Figure 23. Nephogram of the maximum principal stress of the pipes containing cracks at different positions: (a) crown, (b) springline, and (c) invert.

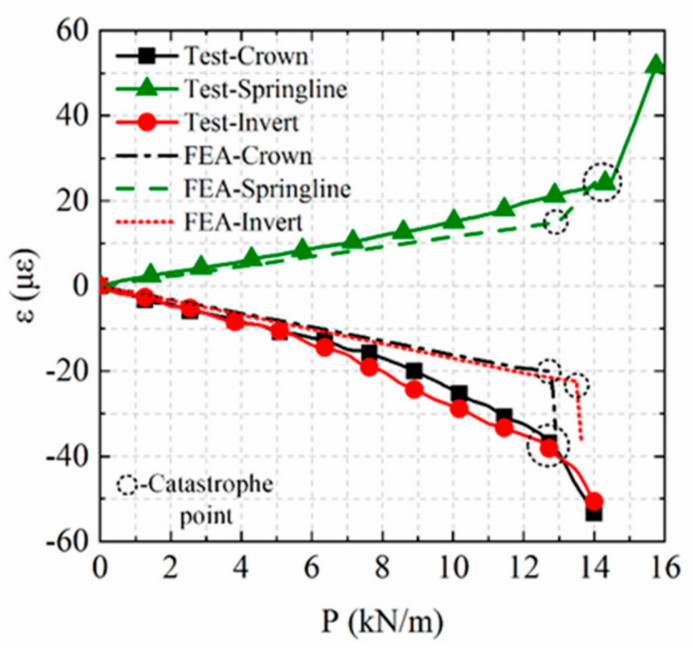

(a)

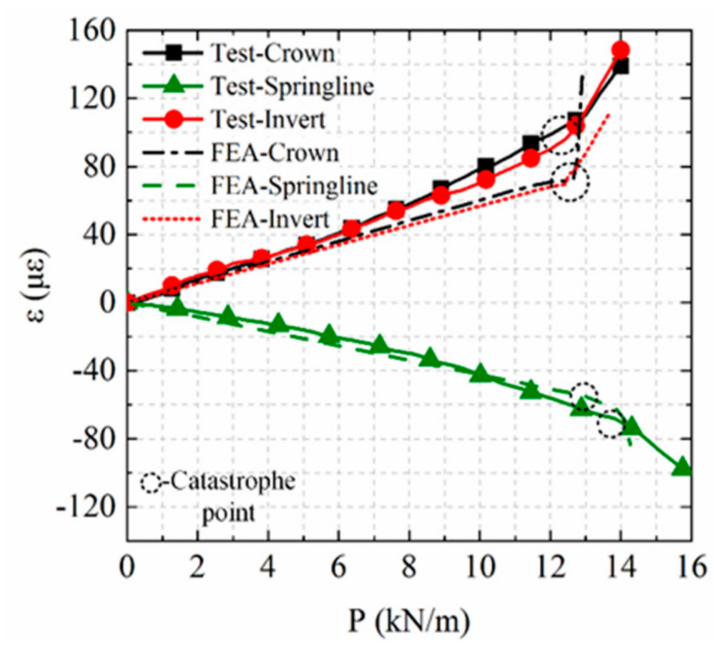

(b)

Figure 24. Load-strain curves of the pipes containing cracks at different positions: (a) outer wall and (b) inner wall.

Furthermore, the simulation data (Figure 24b) reveal that when the crack is located at the crown, springline, and invert, the failure load values of the pipe are $11.7,13.1$, and $12 \mathrm{kN} / \mathrm{m}$ respectively, and their ultimate bearing capacities are reduced by 46,40 , and $45 \%$ respectively. However, the test data show that when the crack is located at the crown, springline, and invert, the failure load values are $12.5,13.6$, and $12.3 \mathrm{kN} / \mathrm{m}$ respectively, which are 46,41 , and $47 \%$ lower than the actual failure load values of the intact pipes.

(2) Circumferential strain 
The circumferential strains on the inner and outer walls of the pipe are extracted under the destructive load at eight positions, and the circumferential strains on the pipe at three different crack positions are analyzed. The strain curves are presented in Figure 25.

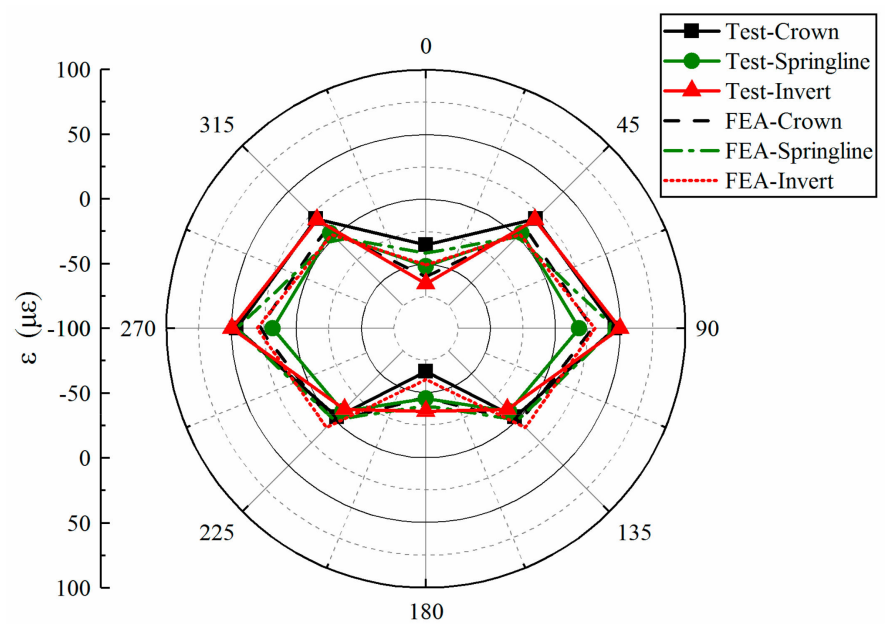

(a)

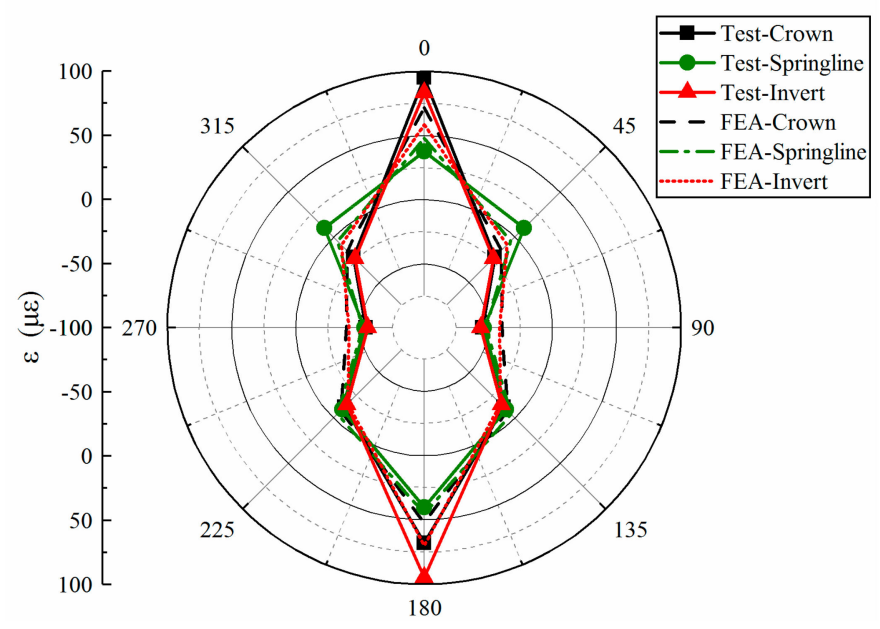

(b)

Figure 25. Circumferential strain curves of the pipes containing cracks at different positions: (a) outer wall and $(\mathbf{b})$ inner wall.

It is clear that the circumferential strain of the inner and outer walls of the pipe is still distributed symmetrically in the center; the circumferential strain on the outer wall of the pipe is distributed as 'concave' from top to bottom and 'convex' from left to right; nevertheless, the circumferential strain on the inner wall of the pipe is distributed as 'convex' from top to bottom and 'concave' from left to right. These findings are consistent with the stress distribution law of concrete pipes under an external load.

The simulation curves in Figure 25a,b show that when the crack is located at the crown $\left(0^{\circ}\right)$, the largest strain is on the inner and outer walls of the crown; however, when the crack is located at the invert $\left(180^{\circ}\right)$, the largest strain occurs on the inner and outer walls of the pipe of the invert; when the crack is located at the springline $\left(90^{\circ}\right)$, the largest strain is again on the inner and outer walls of the crown. Moreover, the strain distribution of the results of the measured curve is approximately consistent with that of the simulated curve, which proves that different crack positions have a great influence on the strain distribution of the pipe. In addition, it can be found out that when the crack is located at the springline $\left(90^{\circ}\right)$, the strain inside and outside the pipe is clearly smaller than when 
the crack is located either at the crown $\left(0^{\circ}\right)$ or at the invert $\left(180^{\circ}\right)$. Also, according to the test, when the crack is located at the springline, the largest ultimate bearing capacity of the pipe is achieved. Therefore, when the crack is located either at the crown $\left(0^{\circ}\right)$ and or at invert $\left(180^{\circ}\right)$, more attention should be paid to the stress condition of the pipe.

Through the comparative analysis of the tests and simulations, the failure loads of the concrete pipes under different working conditions are summarized in Table 6. The vulnerable parts of the concrete pipes are the outer wall at the springline, the inner wall either at the crown or at the invert. Under the action of an external load, the concrete pipe is first destroyed at the crack position. The ultimate bearing capacity of the concrete pipes with cracks is greatly reduced, and the ultimate bearing capacity of the pipes varies with the length, depth, and location of cracks. According to the overall comparison between the experimental and simulated data, the simulated and measured data closely match; however, the mechanical properties obtained by the concrete constitutive model and the experimental concrete pipe are not completely consistent. Moreover, due to the influence of the manufacturing process, field environment, data collection, and other factors, the experimental and simulated data still contain errors.

Table 6. Failure loads of the concrete pipes

\begin{tabular}{|c|c|c|c|c|c|c|c|c|c|c|c|}
\hline \multirow{3}{*}{ Contrast } & \multirow{3}{*}{ Working Condition } & \multirow{3}{*}{$\begin{array}{l}\text { Intact } \\
\text { Pipe }\end{array}$} & \multicolumn{9}{|c|}{ Pre-existing Cracks Pipe } \\
\hline & & & \multicolumn{3}{|c|}{ Crack Length (mm) } & \multicolumn{3}{|c|}{ Crack Depth (mm) } & \multicolumn{3}{|c|}{ Crack Location } \\
\hline & & & 400 & 300 & 200 & 25 & 20 & 15 & Crown & Spring-Line & Invert \\
\hline \multirow{2}{*}{$\begin{array}{l}\text { Numerical } \\
\text { simulation }\end{array}$} & $\begin{array}{l}\text { Average failure load } \\
\qquad(\mathrm{kN} / \mathrm{m})\end{array}$ & 21.7 & 10 & 11.7 & 13.2 & 11.7 & 13 & 13.4 & 11.7 & 13.1 & 12 \\
\hline & Reduction rate (\%) & - & 54 & 46 & 39 & 46 & 40 & 38 & 46 & 40 & 45 \\
\hline \multirow{2}{*}{ Test } & $\begin{array}{l}\text { Average failure load } \\
\qquad(\mathrm{kN} / \mathrm{m})\end{array}$ & 23 & 11 & 12.5 & 14 & 12.5 & 13 & 14 & 12.5 & 13.6 & 12.3 \\
\hline & Reduction rate (\%) & - & 52 & 49 & 43 & 46 & 43 & 39 & 46 & 41 & 47 \\
\hline
\end{tabular}

\section{Conclusions}

In this work, through digital simulation and the mutual verification of the field tests, concrete pipes containing various cracks (different crack lengths crack depths, and crack locations) are studied and analyzed. The main conclusions drawn are as follows:

(1) Through ABAQUS finite element software, the concrete damage plastic model is selected to carry out a numerical simulation analysis on the concrete pipes with pre-existing cracks. Also, using the actual field tests, the simulation results are analyzed and verified. The obtained test results are in good agreement with the simulation data, which indicates that the developed model can well predict the test outcomes.

(2) With the gradual increase of the external load, the circumferential strain on the concrete pipe also rises. The change in strain versus load can be divided into three stages: (i) the elastic stage (in which the load-strain curve shows a linear relationship); (ii) the elastic-plastic stage (in which the load-strain curve displays a nonlinear relationship); (iii) the plastic-failure stage (in which the load-strain curve varies suddenly). Moreover, the elastic-plastic phase occurs for a short time and is not transparently significant, which is due to the fact that concrete is a brittle material, that its compressive strength is far greater than its tensile strength, and that there is no significant plastic deformation stage.

(3) The length, depth, and location of the cracks greatly affect the bearing capacity of the concrete pipes. The greater the length and the depth of the cracks are, the smaller the bearing capacity of the concrete pipe becomes; in fact, the measured failure load values of the pipes containing cracks with a length of 400,300 , and $200 \mathrm{~mm}$ are $11,12.5$, and $14 \mathrm{kN} / \mathrm{m}$ respectively, and their ultimate bearing capacities are reduced by 52,49 , and $43 \%$ respectively. The failure load values of the pipes containing cracks with depths of 25,20 , and $15 \mathrm{~mm}$ are $12.5,13$, and $14 \mathrm{kN} / \mathrm{m}$ respectively, and their ultimate bearing capacities are reduced by 46,43 , and $39 \%$ respectively. When the crack is located either at the crown or at the invert, its influence on the bearing capacity of the pipe is basically the same, and it 
is greater than when the crack is located at the springline; indeed, when the crack is located at the crown, springline, and invert, the measured failure load values of the pipe are 12.5, 13.6, and 12.3 $\mathrm{kN} / \mathrm{m}$ respectively, and their ultimate bearing capacities are reduced by 46,41 , and $47 \%$ respectively.

(4) Stress concentration occurs at both ends of the crack on the pipe with the tip stress far exceeding the apparent stress, causing the local stress to be greatly higher than the allowable stress value of the material. Therefore, in the tests, when the concrete pipes are damaged by the ultimate load, they all break at the crack positions.

(5) However, this study has the following limitations that need further improvement: (i) due to the complicated prefabricated process of pre-existing cracked concrete pipes, the number of pipe samples is insufficient; (ii) the crack prefabrication method needs to be improved and the numerical simulation needs to be further refined; (iii) no repair measures for pipeline cracks have been proposed. Next, the authors will carry out research on repairing and strengthening existing cracked concrete pipes with fiber reinforced polymer (FRP).

Author Contributions: Conceptualization, H.F.; Data curation, Z.Z. and B.L.; Funding acquisition, H.F. and F.W.; Investigation, Z.Z. and B.L.; Methodology, Z.Z.; Software, Z.Z.; Writing一original draft, Z.Z.; Writing-review and editing, B.L. and Z.Z. All authors have read and agreed to the published version of the manuscript.

Funding: This work was supported by the National Key Research and Development Program of China (No. 2016YFC0802400), the National Natural Science Foundation of China (No. 51978630, 51678536), the Program for Science and Technology Innovation Talents in Universities of Henan Province (Grant No. 19HASTIT043), and the Outstanding Young Talent Research Fund of Zhengzhou University (1621323001). The authors would like to thank for these financial supports.

Conflicts of Interest: The authors declare no conflict of interest.

\section{References}

1. Abel, T. Changes in strength parameters of pipelines rehabilitated with close-fit trolining liners-numerical analysis based on laboratory tests. Arch. Civ. Mech. Eng. 2016, 16, 30-40. [CrossRef]

2. Buda-Ozog, L.; Skrzypczak, I.; Kujda, J. Cracks analysis in the reinforced concrete pipes. Balt. J. Road Bridge Eng. 2017, 12, 88-93. [CrossRef]

3. Nourpanah, N.; Taheri, F. Development of a reference strain approach for assessment of fracture response of reeled pipelines. Eng. Fract. Mech. 2010, 77, 2337-2353. [CrossRef]

4. Nourpanah, N.; Taheri, F. Ductile crack growth and constraint in pipelines subject to combined loadings. Eng. Fract. Mech. 2011, 78, 2010-2028. [CrossRef]

5. Robert, D.J.; Rajeev, P.; Kodikara, J.; Rajani, B. Equation to predict maximum pipe stress incorporating internal and external loadings on buried pipes. Can. Geotech. J. 2016, 53, 1315-1331. [CrossRef]

6. Li, C.; Zhong, Z.; Bie, C.; Liu, X. Field performance of large section concrete pipes cracking during jacking in Chongqing-A case study. Tunn. Undergr. Space Technol. 2018, 82, 568-583. [CrossRef]

7. Jayadevan, K.R.; Østby, E.; Thaulow, C. Fracture response of pipelines subjected to large plastic deformation under tension. Int. J. Press. Vessel. Pip. 2004, 81, 771-783. [CrossRef]

8. Lay, G.R.; Brachman, R.W.I. Full-scale physical testing of a buried reinforced concrete pipe under axle load. Can. Geotech. J. 2013, 51, 394-408. [CrossRef]

9. Silva, J.D.; El Debs, M.K.; Beck, A.T. Reliability evaluation of reinforced concrete pipes in crack opening limit state. Rev. IBRACON Estrut. Mater. 2008, 1, 314-330. [CrossRef]

10. BaZant, Z.P.; Cao, Z. Size effect in brittle failure of unreinforced pipes. J. Proc. 1986, 83, 369-373.

11. Hajali, M.; Alavinasab, A.; Shdid, C.A. Structural performance of buried prestressed concrete cylinder pipes with harnessed joints interaction using numerical modeling. Tunn. Undergr. Space Technol. 2016, 51, 11-19. [CrossRef]

12. Brachman, R.W.; Moore, I.D.; Rowe, R.K. The performance of a laboratory facility for evaluating the structural response of small-diameter buried pipes. Can. Geotech. J. 2000, 37, 281-295. [CrossRef]

13. An, C.; Castello, X.; Duan, M.; Toledo Filho, R.D.; Estefen, S.F. Ultimate strength behaviour of sandwich pipes filled with steel fiber reinforced concrete. Ocean Eng. 2012, 55, 125-135. [CrossRef]

14. Hu, S.W.; Liu, X.Y. Overload test and failure mechanism analysis of prestressed concrete cylinder pipe. Shuili Fadian Xuebao (J. Hydroelectr. Eng.) 2012, 31, 103-107. 
15. Hu, S.W.; Shen, J.; Wang, D.L.; Cai, X. Experiment and numerical analysis on super caliber prestressed concrete cylinder pipes with cracks. J. Hydraul. Eng. 2010, 41, 876-882.

16. Zhang, C.J.; Chen, Y.L.; Li, Y.; Wang, J. Study on mechanism and prevention of cracking in prestressed concrete cylinder pipe of large diameter. J. Northwest Sci-Tech Univ. Agric. For. 2005, 33, 93-98.

17. Zhu, J.J.; Hu, S.W. Study on external overload experiment of steel sleeve concrete pipeline (SSCP). Water Resour. Hydropower Eng. 2018, 49, 59-66.

18. Zhao, X.L.; Dou, T.S.; Yan, J.Q.; Wang, R.L. Experimental study on bearing capacity of Longitudinal cracks on the outer surface of PCCP. China Concr. Cem. Prod. 2012, 12, 37-40.

19. Zhu, H.H.; Guo, H.L.; Yan, S.D.; Li, C.F. Study on bearing capacity of buried pipeline containing corrosion defects under external force. J. Saf. Sci. Technol. 2018, 14, 70-75.

20. Dou, T.S.; Cheng, B.Q.; Hu, H.; Xia, S.F.; Yang, J.X.; Zang, Q. The prototype test study of prestressed concrete cylinder pipe structure Deformation law II: The external pressure. J. Hydraul. Eng. 2018, 49, 207-215.

21. Valiente, A. Stress corrosion failure of large diameter pressure pipelines of prestressed concrete. Eng. Fail. Anal. 2001, 8, 245-261. [CrossRef]

22. Lee, J.; Fenves, G.L. Plastic-damage model for cyclic loading of concrete structures. J. Eng. Mech. 1998, 124, 892-900. [CrossRef]

23. Li, B.; Fang, H.; He, H.; Yang, K.; Chen, C.; Wang, F. Numerical simulation and full-scale test on dynamic response of corroded concrete pipelines under multi-field coupling. Construction and Building Materials 2019, 200, 368-386. [CrossRef]

24. Fang, H.; Li, B.; Wang, F.; Wang, Y.; Cui, C. The mechanical behaviour of drainage pipeline under traffic load before and after polymer grouting trenchless repairing. Tunnelling and Underground Space Technology 2018, 74, 185-194. [CrossRef]

25. Zhai, K.; Fang, H.; Fu, B.; Wang, F.; Hu, B. Mechanical response of externally bonded CFRP on repair of PCCPs with broken wires under internal water pressure. Construction and Building Materials 2020, 239, 117878. [CrossRef]

26. General Administration of Supervision, Inspection and Quarantine of the People's Republic of China. GB/T 16752-2017, Test Methods of Concrete and Reinforced Concrete Sewer Pipes; Standards Press of China: Beijing, China, 2017.

27. Li, B.; Fang, H.; Yang, K.; He, H.; Tan, P.; Wang, F. Mechanical Response and Parametric Sensitivity Analyses of a Drainage Pipe under Multiphysical Coupling Conditions. Complexity 2019. [CrossRef]

28. Vazouras, P.; Karamanos, S.A.; Dakoulas, P. Mechanical behavior of buried steel pipes crossing active strike-slip faults. Soil Dyn. Earthq. Eng. 2012, 41, 164-180. [CrossRef]

29. General Administration of Supervision, Inspection and Quarantine of the People's Republic of China. GB/T 11836-2009, Concrete and Reinforced Concrete Sewer Pipes; Standards Press of China: Beijing, China, 2009.

(C) 2020 by the authors. Licensee MDPI, Basel, Switzerland. This article is an open access article distributed under the terms and conditions of the Creative Commons Attribution (CC BY) license (http://creativecommons.org/licenses/by/4.0/). 